Board of Governors of the Federal Reserve System

International Finance Discussion Papers

Number 566

September 1996

\title{
Long-Term Evidence on the Tobin and Fisher Effects: A New Approach
}

\author{
Shaghil Ahmed and John H. Rogers
}

NOTE: International Finance Discussion Papers are preliminary materials circulated to stimulate discussion and critical comment. References in publications to International Finance Discussion Papers (other than an acknowledgment that the writer has had access to unpublished material) should be cleared with the author or authors. 


\begin{abstract}
Using a new approach, we reexamine the empirical evidence on the long-term interactions between inflation and real variables. We find, using over 100 years of U.S. data, that in the long rum the effect of inflation on investment and output is positive (a "Tobin type effect") and the investment rate, and hence the real interest rate. are not independent of inflation. However, over the full sample at least, the variability of the innovations to the stochastic inflation trend is small relative to the variability of the innovations to the productivity and fiscai trends. We conclude that models generating a reverse-Tobin effect, including standard real-business-cycle and endogenous growth models that incorporate money. may nor be the best models for understanding the long-term real effects of inflation.
\end{abstract}




\title{
Long-Term Evidence on the Tobin and Fisher Effects: A New Approach
}

\author{
Shaghil Ahmed and John H. Rogers*
}

\section{Introduction}

Consider a situation in which, with the economy in a low inflation steady state, the rate of inflation falls permanently, say by 2 percentage points. What would be the long-run effects on real economic variables such as output, consumption, the real interest rate, investment and the capital stock? Economic theory provides no clear-cut prediction. On the one hand there is the famous superneutrality result due to Sidruaski (1967). However, Sidruaski's result emerges from a very specific theoretical set-up, requiring, in particular, the strong assumption that consumption and leisure are separable in utility. Indeed, in several theoretical models the superneutrality result breaks down, as inflation can have either positive or negative effects on real variables such as output and investment, depending on the exact assumptions concerning preferences and how money is introduced into the economy. Additionally, in these models the real interest rate may or may not be independent of the rate of inflation in the long run. (see Orphanides and Solow [1990] for a survey.)

Therefore, whether the long-run effect of inflation on the capital stock and output is positive or negative, and whether the real interest rate is independent of inflation or not in the long run are empirical issues. Recently, there has been considerable interest in the existence of, and nature of, the long-run real effects of inflation (e.g. King and Watson [1994] and Akerlof, Dickens, and Perry [1996]). Understanding these effects is crucial for evaluating monetary policy, especially in light of the debate about moving from the current low inflation rate to price stability. ${ }^{1}$

"The authors are staff economists in the Division of International Finance, Board of Governors of the Federal Reserve System. For their helpful comments, we would like to thank, without implicating, Rick Bond, Allan Brunner, David Bowman, Joe Gagnon, Eric Leeper, Jaime Marquez, Enrique Mendoza, Jim Nason, Eric Rasmusen, Chris Waller and workshop participants at the Federal Reserve Board, Indiana University, and Penn State University. This paper represents the views of the authors and should not be interpreted as reflecting the views of the Board of Governors of the Federal Reserve System or other members of its staff.

${ }^{1}$ It may be argued that super non-neutrality is irrelevant in practice because changes in inflation are not observed to be permanent. But this does not appear to be very persuasive. For example, Mishkin (1992) makes the case that it is likely that inflation has a unit root. Studies such as KingWatson are predicated on the existence of permanent shocks to inflation. 
With these considerations in mind, we reexamine the empirical evidence on the long-term interactions between inflation and the real economy, with the goal of sorting out which of the many theoretical channels of the real effects of inflation are empirically more relevant. We ask whether long-term U.S. data are consistent with a "Tobin type effect" or a "reverse-Tobin effect" occurring in response to a once-and-for all permanent change in inflation. We also examine the long-run validity of the "Fisher effect". To be precise, by a "Tobin type effect" we mean that an exogenous increase in inflation leads to an upward jump in the balanced-growth path of the capital stock and therefore investment, whereas the "reverse-Tobin effect" is taken to indicate a downward jump. The "Fisher effect" (Fisher[1930]) holds when the inflation rate has a one-to-one positive effect on the nominal interest rate and, consequently, does not affect the real interest rate. ${ }^{2}$

Our empirical findings are organized in three parts. First, the univariate properties of the data are described and cointegrating vectors are estimated. Hypothesis testing on these cointegrating vectors reveals whether the data are consistent with the Fisher effect holding in the long run or not. Our test relies on the direct correspondence between the capital-output--and hence the investmentoutput--ratio and the real rate of interest in the long run. This correspondence implies that, if the real interest rate is independent of inflation, the latter should have equal effects on investment and output over a long horizon. This is testable using cointegration analysis. Thus, one important novel aspect of our empirical approach is examining the long-run validity of the Fisher effect, without explicitly modelling inflationary expectations. ${ }^{3}$

${ }^{2}$ Sometimes the terms "Fisher relation" and "Fisher effect" are used interchangeably and used to denote the relationship that the nominal rate is the sum of the ex ante real rate and expected inflation. We prefer to call this identity the "Fisher relation", and throughout this paper take the "Fisher effect" to mean, as seems to be more prevalent in the literature, that the real rate is independent of the rate of inflation. As will become clear, the absence of a Tobin or reverse-Tobin effect and the Fisher effect holding are not necessarily the same thing when leisure is endogenous.

${ }^{3}$ Our method does not, of course, shed light on the validity of the Fisher effect at short-to-medium horizons. The results of tests that attempt to do this are sensitive to the modelling of inflationary expectations. 
Second, under certain restrictions, we are able to identify and estimate additional structural parameters, which allow us to retrieve the effects of changes in the exogenous component of inflation on the levels of consumption, investment and output (as opposed to the effects on the consumptionoutput and investment-output ratios, which are obtained from the cointegrating vectors). The identification scheme is similar to King, Plosser, Stock and Watson (1991). The effect on investment allows us to see whether a Tobin or reverse-Tobin effect holds. Our estimates indicate the presence of a Tobin type effect and indicate that the Fisher effect does not hold in U.S. data from 1889-1995. However, the variance decompositions also show that the inflation trend is not particularly important in explaining real economic fluctuations.

Third, and finally, we examine the robustness of our findings over different sub-periods of the data, thus allowing for the possibility that there may have been structural breaks over this long period in the interactions between inflation and real variables.

The remainder of our paper is organized as follows: In section 2, we set up a general framework that nests the different types of effects of inflation on the real economy that are found in the theoretical literature. In this framework, the long-run paths of the variables are driven by three stochastic trends: a productivity (or output) trend, a fiscal trend, and an inflation trend. Section 3 links the theoretical model to our empirical estimation, discusses the identifying assumptions and presents our empirical results. Section 4 concludes.

\section{Theoretical Framework}

There is nothing fundamentally new in the theoretical model we use below. Our objective is to develop a unified framework that is general enough to incorporate many of the relevant theoretical results on the real effects of inflation as special cases. We begin with a brief descriptive review of the theoretical literature, and then proceed to our general framework. ${ }^{4}$

\footnotetext{
${ }^{4}$ Although models with sticky prices and/or imperfect information (e.g., Ball, Mankiw, and Romer
} 


\section{Review of the Literature}

Tobin (1965) first established the portfolio mechanism that generates a positive effect of inflation on the steady-state capital stock. The intuition is that a higher inflation rate induces savers to substitute from holding money to holding physical capital. This mechanism has been dubbed the "Tobin effect". Because the marginal product of capital is lower, the real interest rate falls.

The Tobin effect, as originally formulated, was widely criticized on the grounds that it assumes an exogenous savings rate. ${ }^{5}$ This criticism led to a literature that has shown that a "Tobin type effect"--by which we mean only a positive relationship between inflation and the capital stock-can arise even in optimizing models with certain features. For example, it can arise in two-period OLG models, in infinite horizon models with individual heterogeneity and family disconnectedness due to uncertain lifetimes, and in models with consumption and money entering utility in a nonseparable way under particular assumptions about how the marginal utility of consumption is affected by money. ${ }^{6}$ A positive relationship between inflation and investment can also arise if there are distortions in the tax system. Specifically, Bayoumi and Gagnon (1996) show that if it is nominal capital income, rather than real capital income, that is taxed, as in Feldstein (1976), higher inflation countries will tend to invest more than lower inflation countries, which is consistent with the data. Thus, we do not need to rely on the original, and perhaps implausible, mechanism proposed in the early papers that introduced the Tobin effect, to get a positive effect of inflation on the capital stock and output.

In contrast to models generating a "Tobin type effect", there are a lot of models that generate the reverse-Tobin effect. The simplest one of these is a Sidrauski type model, but with endogenous

[1988]) generate highly persistent effects of inflation, these effects do not last forever and, strictly speaking, long-run superneutrality applies. Hence the remainder of the discussion focuses on flexibleprice models.

${ }^{5}$ Moreover, the mechanism in Tobin's original formulation cannot possibly lead to a large effect of inflation on the capital stock (in percentage terms at least), given plausible values of the interest elasticity of money demand and the ratio of non-interest-bearing money to the capital stock. We thank Joe Gagnon for pointing this out to us.

${ }^{6}$ See the Orphanides and Solow paper, and the literature cited therein, for details. See also Wang and Yip [1992] for the role of nonseparability in utility. 
leisure that is not separable from consumption, and with money introduced through a cash-in-advance (CIA) constraint on consumption (e.g. Cooley and Hansen[1989]). In this set-up, a higher inflation rate taxes consumption more, leading people to switch into nonmarket activity (leisure). This shifts in the marginal product of capital schedule, so that the steady-state capital stock falls. The Fisher effect still applies, though, since the capital-labor ratio is constant in the steady-state. ${ }^{7}$

To simultaneously generate a reverse-Tobin effect and at the same time the Fisher effect not holding, one can consider a CIA model of the Stockman (1981) type with the CIA constraint applying to both consumption and investment. In this case, inflation represents an additional cost to investment and, therefore, a higher inflation rate leads to less investment and an increase in the real interest rate. Abel (1985) derives the above results and compares (abstracting from the labor/leisure choice) the dynamic accumulation of capital in models where the CIA constraint applies only to conusmption and models in which which it applies to both consumption and investment.

Finally, there is the more modern genre of endogenous growth models with money. These models also generate long-run real effects of inflation and the crucial factor is the dependence of the leisure-labor choice on inflation. These endogenous growth models generate a reverse-Tobin effect of the type described above, but they also display some important additional features. Typically, in these models a once-and-for all rise in inflation has a negative effect on the steady-state growth rate of the economy as well. (For example, see Gomme [1993] and De Gregorio [1993]). However, if output growth is stationary, shocks to the random walk component of inflation could not empirically have any significant permanent effect on growth. This raises the question of whether it is possible in optimizing models to have inflation affecting the real interest rate but not the growth rate of the economy in the long run. We will return to this issue later.

7There are also models in which inflation has an ambiguous effect on the steady-state capital stock. Two examples are Fischer (1983), in which money enters the production function, and Brock (1974), in which money enters utility and leisure is endogenous. 


\section{A General Theoretical Framework}

\section{Preferences and Production}

The representative agent's utility function at time $t$ is:

$$
u(.,)=u\left(C_{t}, 1-N_{t}, \frac{M_{t}^{d}}{P_{1}}\right)=\ln C_{1}+\phi_{L} \ln \left(1-N_{t}\right)+\phi_{M} \ln \left(\frac{M_{1}^{d}}{P_{1}}\right)
$$

where $C$ = consumption, $N=$ the fraction of time spent working, $M^{t}=$ desired holdings of money, $P$ is the price level, and $\phi_{L}, \phi_{M}>0$ are preference parameters. The technology is:

$$
Y_{1}=\exp \left\{\phi g_{1}\right\} A_{t}^{\theta} F\left(N_{t}, K_{l}\right) \equiv \exp \left\{\phi g_{1}\right\} A_{t}^{\theta} N_{t}^{\theta} K_{t}^{1 \theta}
$$

where $Y$ is output, $K$ is the capital stock, $A$ is a technology shift variable, $g=G / Y$ represents the size of government with $G$ being aggregate government purchases of goods and services and $\phi, \theta$ are fixed parameters with $0<\theta<1$. The above specification is standard Cobb-Douglas, except that it allows the size of government to affect private production possibilities. ${ }^{8}$ In our theoretical set-up no stance is taken on whether government size shifts the production function up $(\phi>0)$, down $(\phi<0)$, or has no effect $(\phi=0)$. Eq. (2) implies that output available to the private sector, $Y-G$, is given by:

$$
\left(1-g_{1}\right) Y_{t}=\exp \left\{\phi g_{l}\right\}\left(1-g_{1}\right) A_{t}^{\theta} F\left(N_{t}, K_{t}\right) \equiv Z_{t}^{\theta} N_{t}^{\theta} K_{t}^{1 \theta}
$$

where $Z=[\exp \{\phi g\}(1-\mathrm{g})]^{1 / \theta} A$ represents the scale factor for private output.

The Government

The government is subject to the following budget constraint:

$$
g_{1}+\frac{Q_{1}}{P_{1} Y_{1}}=\tau_{1}+\frac{\Delta M_{1+1}}{P_{1} Y_{1}}
$$

where $Q$ is the lump-sum transfer from the government and $M$ is the beginning of period money supply. Multiplying through by $P Y,(4)$ just equates the uses and sources of government funds. Note

\footnotetext{
${ }^{8}$ Barro and Sala-i-Martin (1995) argue that putting government size, rather than the level of government spending, in the production function is appropriate if governmental activities are subject to congestion.
} 
that we have abstracted from government debt. With Ricardian equivalence, our analysis would essentially be unchanged with the introduction of debt.

Even though households take the lump-sum transfers, $Q$, as given, monetary policy makes the transfers proportional to existing money holdings, so that:

$$
Q_{t}=\Delta M_{i+1}=\mu_{M} M_{t}
$$

Eqs. (4) and (5) imply that $g_{t}=\tau$. We assume that agents internalize the government's budget constraint and know that tax rates will be set according to this policy.

\section{Constraints Facing Households}

For simplicity, households are treated as integrated worker-firm units. Since beginning of period t money holdings have already been determined by decisions made at $\mathrm{t}-1, \boldsymbol{M}^{\prime}$, which equals $M$, in equilibrium, is a state variable. Transfer payments, being lump-sum, $Q$, is also a state variable for households. The household's budget constraint, equating the sources and uses of funds is:

$$
Z_{t}^{\theta} F\left(N_{i}, K_{l}\right)+\frac{M_{i}^{a}+Q_{i}}{P_{i}}-\left[K_{t+i}-(1-\delta) K_{l}\right]-C_{t}-\frac{M_{t+1}^{a}}{P_{l}}=0
$$

where $\delta$ is the depreciation rate and we have already substituted $I_{t}=K_{t+1}-(1-\delta) K_{t}$ for investment. ${ }^{9}$

Households also face the following CIA constraint, with a fraction $a_{C}$ of consumption and a fraction $a_{K}$ of investment being financed by cash holdings:

$$
\frac{M_{i}^{d}+Q_{1}}{P}-a_{c} C_{i}-a_{K}\left[K_{t+1}-(1-\delta) K_{i}\right] \geq 0
$$

It seems rather awkward to have money in the utility function as well as a CIA constraint. This is for convenience, in order to have one general set-up from which different models can emerge as special cases. In the cases we consider below, either money provides utility or the CIA constraint is relevant, but never both.

${ }^{9}$ Strictly speaking, (6) should be an inequality constraint. However, we impose standard conditions on preferences and technology that lead to free disposal never being exercised. 


\section{Optimization Problem}

The representative household's optimization problem is to

$$
\max _{\left\{C_{,}, K_{t, 1}, M_{t, i}^{d}\right\}} \sum_{i=0}^{\infty} \beta^{\prime} u\left(C_{t}, 1-N_{t}, \frac{M_{t}^{d}}{P_{t}}\right)
$$

subject to the sequence of constraints (6) and (7). Bellman's recursive representation of the above problem and the first order conditions that emerge are standard and are relegated to Appendix A. The implications of these conditions for steady-state paths are also standard, but since they are important in tightly relating our empirical work to the theoretical literature, we describe them below.

\section{Steady-State Paths}

It can be shown that if, in the long run, $g_{t}$ is expected to be constant at $g$ and if $A_{t}$ is expected to grow at a constant growth rate $\mu_{A}$ - the growth rate of the economy--then the steady-state paths of the economy are characterized by:

$$
\begin{gathered}
\frac{1}{C_{t}}=\lambda_{t}+a_{C} \gamma_{t} \\
\frac{\phi_{L}}{1-N_{t}}=\lambda Z_{t}^{\theta} N_{t}^{\theta-1} K_{t}^{1 \theta} \\
\beta\left[(1-\theta) Z_{t+1}^{\theta} N_{t+1}^{\theta} K_{t+1}^{\theta}+(1-\delta)\right] \lambda_{t+1}+\beta \gamma_{t+1} a_{K}(1-\delta)=\lambda_{t}+a_{K} \gamma_{t} \\
\beta \phi_{M}\left(\frac{P_{t+1}}{M_{t+1}^{d}}\right)+\beta \lambda_{t+1}+\beta \gamma_{t+1}=(1+\pi) \lambda_{t} \\
Z_{t}^{\theta} N_{t}^{\theta} K_{t}^{1 \theta}-\left(\mu_{A}+\delta\right) K_{t}-C_{t}=0 \\
\gamma_{t}\left\{\begin{array}{c}
M_{t}\left(1+\mu_{M}\right) \\
P_{t}
\end{array}-a_{c} C_{t}-a_{K}\left(\mu_{A}+\delta\right) K_{t}\right\}=0
\end{gathered}
$$

where $\lambda_{p} \gamma_{1}$ represent the Lagrange multipliers associated with (6) and (7) respectively, and $\pi$ represents the steady-state growth rate of prices, which is easily shown to be $\mu_{M}-\mu_{A}$. 
Interpretation of these equations is straightforward. Eq. (9) equates the marginal utility loss from foregoing consumption today to the marginal utility gain from having extra income to save plus the marginal utility gain from having the CIA constraint relaxed a little bit. Eq. (10) equates the marginal utility loss from foregoing leisure to the marginal product of labor in utility units.

Eq. (11) results from the tradeoff between current income and end of period money holdings. The left hand side is the marginal benefit of having an additional unit of real balances next period, which consists of the discounted value of three terms--the direct utility obtained from the real balances, the marginal utility from spending real balances next period, and the marginal gain from the relaxation of the CIA constraint next period. The right hand side is the loss from not having the current income available for alternative uses, which consists of the marginal utility of income $\left(\lambda_{t}\right)$ times the amount of today's real income it takes to augment future real balances by one unit $(1+\pi)$.

Eq. (12) equates the marginal benefit of investment to the marginal cost of investment. The marginal cost (the right hand side) is the utility loss from not having the income available for alternative uses plus the utility loss due to CIA requirement. The marginal benefit (left hand side) consists of the discounted value of two terms--the gain in utility from the gross marginal product of capital and the gain in utility that comes about because capital already in place is not subject to CIA.

Eq. (13) is the steady-state version of the resource constraint, equating private output to the sum of consumption and steady-state investment. Finally, (14) states that either the CIA constraint must bind, or the marginal utility of having it relaxed a little bit $\left(\gamma_{1}\right)$ must be zero.

\section{Profit Maximizing Firns and An Implication of the Fisher Effect}

Although households and firms here are integrated, there is an analogue economy in which explicit competitive markets for labor and capital exist. In that economy, the typical firm's profit maximizing condition is:

$$
r_{1}=(1-\theta)\left(\frac{K_{t}}{Z_{r} N_{t}}\right)^{\oplus}-\delta=(1-\theta) \frac{Y_{t}}{K_{t}}-\delta
$$

This equation is very important in justifying our test of the long-run Fisher relation because the 
constancy of $Y / K$ also implies constancy of $\mathrm{Y} / \mathrm{I}$. Hence, we can test for the independence of the real interest rate from inflation in the long run by examining whether changes in inflation have a zero long-term effect on the investment-output ratio. ${ }^{10}$ The equation also clearly shows that when work effort depends on inflation. the Fisher effect holding is not the same property as $K / Z$ being independent of $\pi$; if the effects of $\pi$ on $l / N$ and $K / Z$ are offsetting (as, for example, in Cooley and Hansen), the real rate can be independent of $\pi$ even though $K / Z$ is not.

Four Models as Special Cases

Three special cases of the general model emerge in a straightforward manner:

(i) no CIA constraint $\left(a_{c}=0=a_{K}\right)$. labelled Sidrauski Model:

(ii) CIA for consumption only $\left(\mathrm{a}_{\mathrm{C}}=1, a_{K}=0\right)$, money provides no direct utility $\left(\phi_{M}=0\right)$, which closely resembles Cooley and Hansen, and is labelled The Inflation-Tax-on-Consumption Model;

(iii) CIA for consumption and investment $\left(a_{C}=1=a_{K}\right)$, but with money providing no direct utility $\left(\phi_{M}=0\right)$, which closely resembles the model of Stockman, and is labelled Inflation-Tax-onConsumption-and-Investment Model.

The fourth model we consider motivates the Tobin effect. Although, there are several ways to generate a Tobin-type effect within an optimization model, we proceed in the spirit of the original formulation by making the savings rate exogenous. For simplicity, we fix leisure and drop the CIA constraint. Thus, $N$ is fixed, $a_{\ell^{-}}=0=a_{K}$. and savings is a fixed proportion, $s$, of disposable income, which is the sum of real private output and the change in real balances. Conjecturing that in steadystate $N$ and $M P Z N$ will be constant (which means $\pi=\mu_{N}-\mu_{A}$ ), this implies:

$$
C_{1}=(1-s)\left(Z_{t}^{\theta} N^{\theta} K_{t}^{\mathrm{i} \hat{\theta}}+\mu_{A} \frac{M_{t}}{P_{t}}\right)
$$

Eqs. (13) and (16) imply:

\footnotetext{
${ }^{10} \mathrm{We}$ abstract from income taxes. For the effects of changes in tax rates on investment and growth see Medoza et. al. (1995) and for the interactions between inflation, taxes, and investment see the Bayoumi and Gagnon paper cited earlier.
} 


$$
s(k)^{1+}-\left(\mu_{A}+\delta\right) k^{*}-(1-s) \mu_{i} m^{*}=0
$$

where lower case letters with asterisks denote steady-state values of variables deflated by ZN (i.e. $k^{*}$ is the steady-state value of $K / Z N$. etc). We assume that $M / P$ and $K$ are still optimally chosen. In this new set-up. (A1), (A2), (A6) in the Appendix drop out. (A4) and (A5) are still valid, but the indirect marginal utilities of $M / P$ and $K$ are different. This fourth model is labelled Tobin Model.

These models differ as to the signs of the derivatives of steady-state values with respect to inflation (denoted by the subscript $\pi$ ), as described below:

\section{Long-Term Effects of Inflation}

MODEL

\section{EFFECTS OF} INFLATION
SUPERNEU-

TRALITY?
TOBIN EFFECT?
REVERSE

TOBIN?
FISHER

EFFECT?

\begin{tabular}{|c|c|c|c|c|c|}
\hline I. Sidrauski & $\begin{array}{l}c^{*}{ }_{\pi}=0, k^{*}{ }_{\pi}=0 \\
i^{*}{ }^{*}=0, y^{*}{ }^{*}=0, \\
N^{*}{ }_{n}=0, \quad(l / Z)^{*}{ }_{n}=0\end{array}$ & Yes & No & No & Yes \\
\hline $\begin{array}{l}\text { II. CIA for } \\
\text { Consumption }\end{array}$ & $\begin{array}{l}c^{*}=0, k^{*}=0 \\
i^{*}=0, y^{*}{ }_{\pi}=0 \\
N^{*}{ }_{\pi}<0,(I / Z)^{*}{ }_{n}<0\end{array}$ & No & No & Yes & Yes \\
\hline $\begin{array}{l}\text { III. CIA for } \\
\text { Consumption } \\
\text { \& Investment }\end{array}$ & $\begin{array}{l}c^{*}{ }_{\pi}<0, k^{*}{ }_{\pi}<0, \\
i^{*}{ }_{\pi}<0, y^{*}{ }_{\pi}<0, \\
N^{*}{ }_{\pi}<0,(I / Z)^{*}{ }_{\pi}<0\end{array}$ & No & No & Yes & No \\
\hline IV. Tobin" & $\begin{array}{l}c^{*}(?), k^{*}>0, \\
\mathrm{i}_{\pi}>0, \mathrm{y}^{*}>0, \\
N_{\pi}^{*}=0,(I / Z)_{\pi}^{*}<0\end{array}$ & No & Yes & No & No \\
\hline
\end{tabular}

The superneutrality property of the Sidrauski model is well-known. ${ }^{12}$ The negative effect of

"With exogenous work effort, $N_{n}=0$ holds by assumption. In general, in a Tobin type model, the negative effect of inflation on work effort, tending to counter the positive direct effect on investment output, could be present. We assume the stability condition $s(l-\theta) k^{-\theta}<\mu_{A}+\delta$ holds.

${ }^{12}$ Note that superneutrality is generally taken to mean that all real variables except real balances are determined independently from inflation, which is how we use the term in this paper. 
inflation on work effort in the CIA-on-consumption model is intuitive: inflation acts as a tax on consumption, inducing households to substitute into leisure. However, in the long run the real interest rate is still independent of inflation in this model. The real rate, from constant returns to scale, depends only on the capital-output ratio, which in the long run is independent of inflation, since the CIA constraint does not apply to investment. Since inflation does decrease work effort, $k^{*}=(K / Z N)^{*}$ being independent of inflation, implies a downward shift in the balanced-growth path of $K$ (i.e. a fall in $K / Z)^{*}$. When the CIA constraint applies to investment also (Model III) the capital-output ratio falls in response to inflation and the real rate rises. This is because inflation acts as a tax on investment also in this case.

The essential intuition behind the results in the Tobin model can be seen by considering (17). As long as the stability condition $s(1-\theta) k^{-\theta}<\mu_{A}+\delta$ holds, anything (including inflation) that decreases steady-state effective per capita real balances, $m^{*}$, must increase the effective per capita capital stock, $k^{*}$. If $k^{*}$ rises, the real interest rate, of course, falls.

\section{The Empirical Framework and Results}

\section{The Data}

Our data consists of annual observations from the U.S.from 1889 to 1995 . Output, consumption, investment, and government spending on goods and services are per capita billions of 1987 dollars. Inflation is the log first-difference of the GDP deflator. Total resident population is used to obtain per capita values. The notation used in reporting the empirical results is as follows: $y$, $\mathrm{c}$, and $\mathrm{i}$ are the per capita logs of real output, real consumption, and real investment, respectively, $\mathrm{G} / \mathrm{Y}$ is the ratio of real government spending to output, and $\pi$ is inflation. The data appendix contains additional details and lists the sources.

Table 1 reports summary statistics. Over the full sample 1889-1995, inflation averages $3.05 \%$, while the share in total GDP of government spending, consumption, and investment is $19.4 \%$, 
$63.8 \%$, and $16.6 \%$, respectively. As is well-known, and as can be seen from the plots in figure 1 , there have been dramatic shifts in inflation and the real variables during sub-periods of our sample. The Great Depression era, for example, is well-known as a time of deflation and very low investment. The pre-World War I period, on the other hand, is characterized by low inflation (an annual average rate of $0.81 \%$ ) and high investment $(22.9 \%$ of GDP), as indicated by column 2 of table 1 . Our postWWII period reflects the opposite, with a $4.30 \%$ average inflation rate and $15.8 \%$ investment share. The share of consumption in total output has remained fairly steady over the different sub-periods.

\section{Univariate Properties}

The use of per capita data for output, consumption, and investment amounts to deflating the aggregate quantities of these variables by the deterministic component of the trend in work effort. ${ }^{13}$ The representative agent theoretical framework laid out earlier presumes that the variables $y, c, i$, G/Y and $\pi$ have stochastic trends embedded in them (i.e. have unit roots). We conduct three types of univariate analysis to evaluate this prior: looking at plots of the data, examining the autocorrelations, and conducting more formal unit root tests.

Figure 1 plots the deterministically detrended logs of per capita output, consumption, investment and also plots government size, inflation and the nominal interest rate. The nominal interest rate data is provided for the purpose of comparison with inflation. Detrended per capita output, consumption and investment appear to be nonstationary. The question of the stationarity, or otherwise, of government size and inflation is not so clear-cut from the plots of the data. Plots of the first differences (not reported) give a strong indication that the differences are stationary.

The autocorrelations of the variables displayed in figure 1 are plotted in figure 2 . The autocorrelations of the detrended per capita levels of consumption, investment, output, and government size do not die away quickly, again indicating nonstationarity. The autocorrelations of

\footnotetext{
${ }^{13}$ An alternative procedure would be to instead use aggregate levels, but include a time trend separately in the cointegrating $(\mathrm{CI})$ vectors. Results from estimating $\mathrm{CI}$ vectors with this alternative procedure are not reported, but briefly discussed in the text later.
} 
inflation take about 4 years to die away, which is quicker than the rate at which the detrended output, consumption, and investment autocorrelations die away, but slower than the rate at which the autocorrelations of the first differences (not shown) die away. ${ }^{14}$

Table 2 reports the results of two formal tests for unit roots: the augmented Dickey Fuller (ADF) test, which has the unit root as the null hypothesis (Dickey and Fuller [1979]), and the KPSS test, for which the null is stationarity or trend-stationarity (Kwiatowski, Phillips, Schmidt and Shin [1992]). The trend is not included in the case of the government size variable, since this ratio is bounded between 0 and 1 . The results are contained in the first four columns. There is substantial evidence for unit roots in per capita values of output, consumption, investment, and government size, but the results on inflation are very borderline and sensitive to the exact sample period used. Because some of the series display unusual dynamics during the wars, we also conducted ADF tests allowing interaction of the lagged first differences with a wartime dummy in the Dickey-Fuller regressions. This essentially allows the wartime dynamics to be different from the rest of the sample period. The results, reported in the final column, indicate unit roots in all the variables.

We thus proceed with the maintained hypothesis of unit roots in $y, c, i$, and $\pi$. In the case of $\mathrm{G} / \mathrm{Y}$, we alternatively report results both under the assumption of a unit root and stationarity. There are two factors that affected our decision in this respect. First, many of the models that consider the effects of fiscal policy in a general-equilibrium setting, assume that $G / Y$ is mean-reverting, although deviations from the mean value may be very persistent. (See, for example, Baxter and King [1993].) Second, although our univariate tests do support the unit root in $G / Y$, the tests are based on an assumption of a linear process, whereas this variable--being a ratio bounded between 0 and 1--cannot be a restriction-free linear unit root process.

We also realize that the question of a unit root in inflation is controversial. However, there is a vast theoretical literature analyzing the real effects of once-and-for-all unanticipated changes in

\footnotetext{
${ }^{14}$ The first difference plots are omitted to conserve space, since what they indicate--that the variables plotted in figure 1 are not integrated of order higher than one--is unlikely to be controversial.
} 
inflation and whether a long-run inflation-unemployment tradeoff can exist or not. This literature puts a very strong prior on a unit root in inflation. Moreover, there are empirical results that are sympathetic to unit roots in inflation (See, for example, Mishkin [1992] and King and Watson [1994]). Barsky (1987) has also argued that since 1914, shocks to inflation have become more persistent, particularly in the post-war period. Given these considerations and the borderline nature of our own tests, we proceed with the assumption of a unit root in $\pi$.

\section{The General Model in a Stochastic Environment}

The univariate analysis suggests the presence of stochastic trends. Therefore, for empirical implementation, we now discuss the extension of our analysis above to allow once-and-for-all permanent shocks to the productivity trend, the government size trend, and the inflation trend. It is convenient to separate out the trend and cyclical components of our variables. For the variables $A, g$ and $\pi$--with a bar over the variable indicating the trend component and a tilde denoting the cyclical component (the deviation from the steady-state path)-- we have:

$$
\ln A_{t}=\ln \bar{A}_{t}+\tilde{a}_{t} ; \quad g_{t}=\bar{g}_{t}+\tilde{g}_{t} ; \quad \pi=\bar{\pi}_{t}+\tilde{\pi}_{t}
$$

Invoking certainty equivalence, we can still characterize the steady-state path of the economy by (9)(14) (with the implications for the different models summarized in the panel on p.11), provided we replace the (previously constant) steady-state inflation rate by its expected value. The latter, from the random walk property of stochastic trends, is the current permanent component, $\pi_{t}$ with a bar over head. With this change, which implies that the long-run paths $c^{*}, k^{*}$, etc. now have time subscripts, we can write:

$$
\begin{gathered}
c_{t}^{*} \equiv\left(\frac{C_{t}}{Z_{t} N_{t}}\right)^{*}=c\left(\bar{\pi}_{t}\right) ; \quad k_{t}^{*} \equiv\left(\frac{K_{t}}{Z_{r} N_{t}}\right)^{*}=k\left(\bar{\pi}_{t}\right) ; \quad i_{t}^{*} \equiv\left(\frac{I_{t}}{Z_{t} N_{t}}\right)^{*}=i\left(\bar{\pi}_{t}\right) ; \\
y_{t}^{*} \equiv\left[\frac{Y_{t}\left(1-g_{t}\right)}{Z_{t} N_{t}}\right]^{*}=y\left(\bar{\pi}_{t}\right) ; \quad N_{t}^{*}=N\left(\bar{\pi}_{t}\right) ; \quad m_{t}^{*}=m\left(\bar{\pi}_{t}\right) .
\end{gathered}
$$

Note that $y^{*}$ is long-run effective per capita private, rather than total, output. 
For estimation, we postulate linear relationships between the logs of the variables on the left hand side of side of (19) and the permanent component of inflation. Given this, (18), (19), and the definition of $Z$ (which implies $\ln Z=(\phi / \theta) g+(1 / \theta) \ln (1-g)+\ln \mathrm{A} \approx \ln A-[(1-\phi) / \theta] g$ ), yield:

$$
\begin{gathered}
\ln C_{t}=\ln \bar{A}_{t}-\alpha_{C} \bar{g}_{t}+\left(\beta_{N}+\beta_{C}\right) \bar{\pi}_{t}+\left\{\tilde{a}_{t}+\tilde{c}_{t}+\tilde{n}_{t}-\alpha_{C} \tilde{g}_{t}\right\} \\
\ln I_{t}=\ln \bar{A}_{t}-\alpha_{t} \bar{g}_{t}+\left(\beta_{N}+\beta_{t}\right) \bar{\pi}_{t}+\left\{\tilde{a}_{t}+\tilde{i}_{t}+\tilde{n}_{t}-\alpha_{l} \tilde{g}_{t}\right\} \\
\ln Y_{t}=\ln \bar{A}_{t}+\left(1-\alpha_{Y}\right) \bar{g}_{t}+\left(\beta_{N}+\beta_{Y}\right) \bar{\pi}_{t}+\left\{\tilde{a}_{t}+\tilde{y}_{t}+\tilde{n}_{t}-\left(1-\alpha_{Y}\right) \tilde{g}_{t}\right\}
\end{gathered}
$$

where a tilde over a variable represents its deviation from the steady-state path, so that the terms in curly brackets in (20)-(22) represent stationary components that are constant along steady-state paths. In our long-term data set, $N$ is an unobserved variable, and so we have substituted out for it. Also, we do not report the analogous equation for $K$, since the capital stock is also unobservable in our data. Eqs. (20)-(22) imply the two independent cointegrating (CI) relationships given below:

$$
\alpha^{\prime} X_{t} \equiv\left[\begin{array}{lllll}
\alpha_{C}-\left(1-\alpha_{Y}\right) & -\left(\beta_{C}-\beta_{Y}\right) & -1 & 1 & 0 \\
\alpha_{1}-\left(1-\alpha_{Y}\right) & -\left(\beta_{l}-\beta_{Y}\right) & -1 & 0 & 1
\end{array}\right]\left(\begin{array}{c}
g_{t} \\
\pi_{t} \\
\ln Y_{t} \\
\ln C_{t} \\
\ln I_{t}
\end{array}\right) \quad I(0)
$$

These long-term relationships can be estimated and we can test whether or not the Fisher effect holds by testing the null hypothesis $H_{\eta}: \beta_{I}-\beta_{Y}=0$. It is also clear from (23) that the restrictions $\alpha_{Y}=\alpha_{C}$ $=\alpha_{l}$ are overidentification restrictions; they set the coefficient on $g$ in the two CI vectors to unity, which can be tested, given that these restrictions are not needed for identification. ${ }^{15}$

Thus, we estimate the following CI relationships using the maximum-likelihood Johansen method (see Johansen and Juselius [1992]), as implemented in the PCGIVE statistical package:

${ }^{15}$ Our particular theoretical set-up implies that $\alpha_{C}=\alpha_{I}=\alpha_{Y}=(1-\phi) / \theta$, but, with more generality, e.g. when government spending enters utility in a nonseparable way, these restrictions will not necessarily hold. 


$$
\beta_{11} g_{t}+\beta_{12} \pi_{t}+\beta_{13} \ln Y_{t}+\ln C_{t}=e_{1 t} ; \quad \beta_{21} g_{t}+\beta_{22} \pi_{t}+\beta_{23} \ln Y_{t}+\ln I_{t}=e_{2 t}
$$

where $e_{\mathrm{i}}, \mathrm{i}=1,2$, is the stationary deviation from the ith cointegrating (long-term) relationship. If the cointegrating rank is two, the estimated cointegrating vectors can be thought of as two linear combinations of the vectors given in (23). If we normalize the coefficient on $\ln C$ in the first estimated vector and the coefficient on $\ln I$ in the second estimated vector to be unity, then comparing two linear combinations of (23) with the estimated vectors will provide eight equations in eight unknowns.

Hence, the structural cointegrating relationships are just identified. Any further restrictions placed on the $\beta$ coefficients are potentially testable. Our model implies the following restrictions on the $\beta$ coefficients: $\beta_{11}=1=\beta_{21}, \beta_{13}=-1=\beta_{23}, \beta_{12}=\beta_{C}-\beta_{Y}, \beta_{22}=\beta_{1}-\beta_{Y}$. When the Fisher effect holds, we also have $\beta_{22}=0=\beta_{12}$.

\section{Cointegration Test Results and Evidence on the Fisher Effect}

We first examine the cointegrating rank for both the three-trend specification (in which $\mathrm{G} / \mathrm{Y}$ is treated as nonstationary) and the two trend specification (stationary G/Y). The results are in table 3 . The lag length in the VAR was selected starting with a lag length of five and sequentially eliminating lags with F-tests used to check the validity of each reduction. The null hypothesis of $\mathrm{p}$ cointegrating vectors $(\mathrm{CI}$ rank $=\mathrm{p})$ is tested against the alternative of $\mathrm{p}+1$ cointegrating vectors using the maximum eigenvalue test statistic, and the more general alternative of at least $\mathrm{p}+1$ cointegrating vectors using the trace statistic. The values of the maximum eigenvalue and trace statistics are reported both with and without a small sample correction due to Reimers (1992).

For the three-trend specification, a cointegrating rank of 2, which is implied by the theoretical model, is consistent with the results reported in the upper half of table 3. (The exception is a borderline rejection if the trace statistic is used without the degrees of freedom (df) correction. ${ }^{16}$ ) The results for the two trend specification in the lower part of table 3 are even stronger. The null of one

${ }^{16}$ There does not appear to be any consensus yet on whether Reimer's degrees-of-freedom correction is the preferred correction. 
(or fewer) $\mathrm{CI}$ vector is strongly rejected with or without the $\mathrm{df}$ correction, while the null of two CI vectors cannot be rejected.

We take these results to indicate that the assumption that the $\mathrm{CI}$ rank is two, implicit in our theoretical model, is not at odds with the data.

Table 4 displays our estimates of the cointegrating vectors: one for the 5-variable system of the theoretical model and another for the 4-variable system, in which $G / Y$ is treated as a stationary variable. ${ }^{17}$ Recall that our theoretical model puts some overidentifying restrictions on the CI relationships given in (24). Specifically, the coefficient on output should be -1 and the coefficient on government size should be 1 . We began by testing these overidentifying restrictions. The restriction on the government size variable is rejected most of the time. The restriction on the output variable is also rejected often. However, this is because, despite the fact that the coefficients are close to the predicted value ( -1.07 and -0.99 in the two vectors of the 5-variable system), they have small standard errors (.02 and .09). This is seen in the last row of table 4. The joint restriction of a unit coefficient on output in both vectors is rejected at any level of significance. Based on economic significance, however, these restrictions could be claimed to be satisfied. One should bear in mind that it is possible for a more general specification of our theoretical model in which the coefficient on $G / Y$ is not unity (e.g. if government spending enters utility in a nonseparable manner). By contrast, economic theory considerations put a very strong prior on the -1 coefficient on output; it arises from productivity changes leading to balanced growth. In light of the above, we proceed to estimate the cointegrating vectors with the output variable restricted and $G / Y$ unrestricted.

The estimated structural cointegrating vectors are reported in table 4. For the five-variable model, keeping fixed the effects of government size, a permanent increase in inflation is associated with a drop in the consumption-output ratio and a rise in the investment-output ratio. The coefficient

\footnotetext{
${ }^{17}$ We report the results for the per capita specification only. However, we also conducted our analysis for the level specification, with a time trend included in the cointegrating vectors, for the full sample model at least, with quite similar results.
} 
estimates are statistically significant at customary levels. They indicate that a permanent one percentage point increase in inflation is associated with a long-run drop in the consumption-output ratio of about four percent and rise in the investment-output ratio of about five and one-half percent. This translates into a drop in the share of consumption in total GDP of about 2.5 percentage points and rise in the investment share of about 1.0 percentage point, using as initial shares the full-sample means reported in table 1 . These estimates are large, as they imply that a permanent, one standard deviation change in the rate of inflation $(5.54 \%$ according to table 1$)$ is associated with approximately a one standard deviation change in $I / Y$ and considerably more than a one standard deviation change in $\mathrm{C} / \mathrm{Y}$ (which are 5.40 and 5.41, respectively). Table 4 also reports the results from the four-variable specification in which government size is stationary. Here too the estimated vectors imply a positive (negative) relationship between inflation and investment (consumption). The point estimates in the 4variable specification are of the same sign as in the 5 -variable system and are also significant. The coefficient on consumption is noticeably larger in the 4-variable system.

The results of table 4 are consistent with the Fisher effect not holding: in the long run, the capital-output ratio rises, and therefore the real interest rate falls, as inflation rises. ${ }^{18}$ Since, typically, models in which the real interest rate falls with higher inflation, are ones in which the Tobin effect holds, this would also seem to provide some indirect evidence on the existence of a Tobin-type effect. However, as emphasized earlier, the mechanism which generates this Tobin-type effect can, in principle, be different from that emphasized in Tobin's original specification, since endogenous savings rate models can also generate this type of effect under certain conditions.

\footnotetext{
${ }^{18}$ If we choose values for the parameters $\theta, \delta, \mu_{A}$, then we can use our estimated effect of $\pi$ on $I / Y$, eq. (15), and the steady-state relationship $I / Y=\left(\mu_{A}+\delta\right) K / Y$ to determine the effect of inflation on the steady-state real rate of interest. When we do such calculations for plausible parameter values and over the full sample period, the effect on the real rate is implausibly large. However, introducing quadratic adjustment costs to changing the capital stock modifies (15) and yields more plausible effects of inflation on the real rate. We do not report these numbers because the range varies widely depending on the size of the adjustment costs, which is difficult to pin down. Also, our estimates for the post-WWII sub-period shown below would provide more plausible effects.
} 


\section{Testing the Tobin Effect: Modelling the Stochastic Trends}

The analysis so far, based on estimated cointegration vectors, does not tell us about the direction of causation between inflation and the real variables. In order to interpret results more cleanly in light of our theoretical framework, we need to identify exogenous shocks to inflation, which requires additional identifying assumptions. This also allows us to test for the Tobin or reverse-Tobin effect directly. We begin by modelling the relationship among our stochastic trends:

$$
\begin{gathered}
\bar{g}_{t}=\bar{g}_{t-1}+\varepsilon_{g_{t}} \\
\ln \bar{A}_{t}=\mu_{A}+\ln \bar{A}_{t-1}+\varepsilon_{A t} \\
\bar{\pi}_{t}=\bar{\pi}_{1 t}+\beta_{G} \bar{g}_{t} ; \quad \bar{\pi}_{1 t}=\left(\mu_{M}-\mu_{A}\right)+\bar{\pi}_{1, t-1}+\varepsilon_{\pi t}
\end{gathered}
$$

where the $\varepsilon$ 's are zero-mean, serially uncorrelated disturbance terms. Eqs. (25) and (26), respectively, imply that the productivity trend and the long-run size of government are exogenously given, to the inflation trend at least. Additionally, the stochastic part of the productivity trend is constrained not to affect inflation in the long run. We allow for the fiscal trend to affect steady-state inflation $\left(\beta_{G} \neq 0\right)$. The interpretation of the sign of $\beta_{G}$ is that it represents whether the inflation tax is complementary to $\left(\beta_{G}>0\right)$ or substitutable with $\left(\beta_{G}<0\right)$ general income taxation.

A key issue before we proceed is whether the restrictions embedded in (25)-(27) are consistent with reasonable theoretical models or not. There are two considerations. First, does it make sense that the stochastic part of the productivity trend does not affect inflation in the long run? Second, is it possible that a permanent change in inflation can have a long-run effect on the investment rate--and hence the real interest rate--but no long-run effect on the growth rate of the economy? We discuiss each of these questions in turn.

On the first point, economic theory provides a clear-cut answer: once-and-for-all permanent shocks to the supply of output affect the long-run price level but not its long-run rate of change. Of course, economic theory considerations also dictate that the drift in output, $\mu_{A}$, influences steady-state inflation, but we allow for this in (27). This suggests that the first restriction is sensible. 
On the second point, it would appear that if the inflation rate affects the real interest rate, then it must also affect the long-term growth rate from the standard consumption intertemporal efficiency condition. But this is not true in general. Conjecturing that in the steady-state the growth rate of the economy is equal to $\mu_{A}$, the growth rate of $Z,(10),(13)$, and (15) can be used to show that:

$$
\beta(1+r)=\left(1+a_{K} \frac{\gamma}{\lambda}\right)\left(1+\mu_{A}\right)-\beta \frac{\gamma}{\lambda} a_{k}(1-\delta)
$$

Eq. (28) reduces to the familiar $\beta(1+r)=\left(1+\mu_{A}\right)$ with log-utility, $O N L Y$ when the CIA constraint does NOT apply to investment $\left(a_{K}=0\right)$. But those are also the cases (Models I or II) when the real rate of interest is independent of inflation. When CIA applies to investment also, it is feasible to have a steady-state in which the real rate of return depends on inflation, yet $\mu_{A}$ does not, since the ratio of the Lagrange multipliers $\gamma / \lambda$ also depends on inflation and enters the intertemporal efficiency condition.

Thus, our empirical work, that treats the growth rate of the economy as stationary, admits of all the four models we discussed earlier. It is also consistent with the univariate properties of output growth as well as cross-sectional evidence that has found only small growth rate effects of inflation-such as Barro (1991). ${ }^{19}$ It also admits of the endogenous growth class of models with money, provided the parameterization is such that we can have significant effects of inflation on the investment rate, yet the growth rate effects are negligible. ${ }^{20}$

Following much of the inflation and growth literature, we have not modelled monetary policy explicitly here. However, implicitly, one natural interpretation of the permanent shock to inflation $\left(\varepsilon_{\pi}\right)$ is changes in the monetary authority's target inflation rate. In keeping with the spirit of relating our empirical model to the theoretical literature on the real effects of inflation, we will, for the most

\footnotetext{
${ }^{19}$ There is some empirical evidence, though, of a more significant negative relationship between inflation and growth for high inflation countries. For example, De Gregorio (1993) documents such a relationship for the Latin American countries.

${ }^{20}$ There certainly are endogenous growth models where the investment rate has a unit root, yet the growth rate effects of this unit root can be small with suitable parameterization. (See, for example, the Mendoza et. al. paper mentioned earlier, although the source of the unit root in the investment rate in that work is tax rates, rather than inflation).
} 
part, refer to $\varepsilon_{\pi}$ as an inflation shock, rather than explicitly as a money supply growth shock.

\section{The Estimated VECM}

The vector of our five observed variables, $X$, can now be thought of as being determined by the three permanent innovations to the stochastic trends, $\varepsilon_{g,} \varepsilon_{\pi v} \varepsilon_{A t}$ and two transitory disturbances, which we label $\varepsilon_{l t}{ }^{T}, \varepsilon_{2 t}{ }^{T}$. In moving average form, the structural empirical model now becomes:

$$
\Delta X_{t}=\theta(L) \varepsilon_{t}
$$

where $\varepsilon=\left(\varepsilon_{g} \varepsilon_{\pi} \varepsilon_{A} \varepsilon_{1}^{T} \varepsilon_{2}{ }^{T}\right)^{\prime}$. The theoretical framework with the implied CI relationships given by (23) means that the matrix of long-run multipliers, $\theta(1)$--obtained by setting $L=1$ in $\theta(L)$--is:

$$
\theta(1)=\left(\begin{array}{ccccc}
1 & 0 & 0 & 0 & 0 \\
\beta_{G} & 1 & 0 & 0 & 0 \\
\beta_{G}\left(\beta_{N}+\beta_{Y}\right)+\left(1-\alpha_{Y}\right) & \beta_{N}+\beta_{Y} & 1 & 0 & 0 \\
\beta_{G}\left(\beta_{N}+\beta_{C}\right)-\alpha_{C} & \beta_{N}+\beta_{C} & 1 & 0 & 0 \\
\beta_{G}\left(\beta_{N}+\beta_{I}\right)-\alpha_{I} & \beta_{N}+\beta_{I} & 1 & 0 & 0
\end{array}\right) \equiv[\theta \vdots 0] \equiv[\tilde{\theta} \Gamma \vdots 0]
$$

where 0 is the $5 \times 2$ null matrix and

$$
\tilde{\theta}=\left(\begin{array}{ccc}
1 & 0 & 0 \\
0 & 1 & 0 \\
1 & 0 & 1 \\
-\left(\alpha_{C}-\alpha_{Y}\right) & \left(\beta_{C}-\beta_{Y}\right) & 1 \\
-\left(\alpha_{I}-\alpha_{Y}\right) & \left(\beta_{I}-\beta_{Y}\right) & 1
\end{array}\right) ; \quad \Gamma=\left(\begin{array}{ccc}
1 & 0 & 0 \\
\beta_{G} & 1 & 0 \\
\beta_{G}\left(\beta_{N}+\beta_{Y}\right)-\alpha_{Y} & \beta_{N}+\beta_{Y} & 1
\end{array}\right)
$$

Thus, in (30), the matrix $\theta$ is the product of a matrix consisting of known coefficients (since $\beta_{C}-\beta_{Y}, \beta_{I}-\beta_{Y}, \alpha_{Y}-\alpha_{C}$, and $\alpha_{I}-\alpha_{Y}$ can be obtained from the estimates of the cointegrating vectors) and a lower triangular matrix. In addition, assume, that the permanent innovations, $\varepsilon_{g p} \varepsilon_{\pi p} \varepsilon_{A t}$ are orthogonal to each other. Under these properties, it can be shown that the parameters $\beta_{G},\left(\beta_{N}+\beta_{\gamma}\right)$, $\left(\beta_{N}+\beta_{C}\right),\left(\beta_{N}+\beta_{\nu}\right), \alpha_{Y}, \alpha_{C}, \alpha_{1}$ are identified, and can be retrieved from the reduced-form vector errorcorrection model (VECM).

The formal proof of identification is very similar to that in King et al. (1991) and is given in Appendix B. The intuition of why these parameters are identified lies in the recursive nature of the 
long-run model. Specifically, since the government size trend is causally prior to inflation and independent of the productivity trend, the long-term behavior of $g$ will identify this trend. Accounting for the effect of this trend on inflation, the long-term behavior of inflation then identifies the inflation trend. Similarly, accounting for the long-run effects of inflation and government size on consumption, investment, and output, the long-run behavior of any one of these three variables identifies the productivity trend. The reason that any of the three variables can be used to identify the productivity trend is that the long-run responses of these three variables to the productivity trend are constrained to be equal from the cointegrating vectors imposed.

Thus, under the assumptions that (i) the productivity trend is independent of the fiscal and inflation trends and (ii) the fiscal trend is causally prior to the inflation trend, we can identify the long-run effects of exogenous shocks to inflation on the log-levels of consumption, investment and output $\left(\beta_{N}+\beta_{C}, \beta_{N}+\beta_{I}, \beta_{N}+\beta_{Y}\right.$, respectively). Moreover, for the specifications in which $\mathrm{G} / \mathrm{Y}$ is nonstationary, $\beta_{G}$ is also identified. However, since we have rejected the unitary restriction on $G / Y$, $(1-\phi) / \theta$ is not identified.

\section{Coefficient Estimates: Evidence on the Tobin Effect}

The point estimates and standard errors of the $\beta$ parameters are reported in table 5 . Estimates from both the five-variable and four-variable models indicate that a Tobin type effect is present: a permanently higher inflation rate increases output, investment, and consumption $\left(\beta_{Y}, \beta_{C}, \beta_{I}>0\right)$. With the exception of $\beta_{C}$, which is borderline, these are all statistically significant. Our time-series evidence on investment thus complements the cross-sectional results of Bayoumi and Gagnon, who find that higher inflation countries tend to invest more.

We also find that $\beta_{l}>\beta_{Y}>\beta_{C}$, so that a rise in inflation leads to a rise in the investmentoutput ratio and drop in the consumption-output ratio, just as in the case of the estimates of table 4 . Because the estimated cointegration vectors are imposed in estimating the VECM, the magnitudes of the ratio changes are the same as in table 4: a permanent one percentage point increase in inflation is 
associated with a long-run drop in the share of consumption in total GDP of about 2.5 percentage points and rise in the investment share of about 1.0 percentage point. This would again suggest that the Fisher effect does not hold in the long run. Finally, we find that $\beta_{G}>0$, indicating that the revenue creation function of inflation is used in a complementary fashion to other taxes. This is consistent with the idea of spreading a tax increase over different types of taxes, including inflation. Variance Decompositions: Evidence on the Importance of Inflation Shocks

Table 6 displays the fraction of the forecast error variance of each variable that is attributable to the three permanent shocks: fiscal, inflation, and output shocks. The effects of the inflation shock in the five-variable model are reported in part B of table 6A. The inflation shock accounts for no more than twenty percent of the forecast error variance of either output or investment, and no more than six percent of the error variance of consumption, at any horizon. Most of these point estimates are insignificantly different from zero. Fiscal shocks account for most of the variance of $G / Y$, and a sizable amount of the variance of inflation and output, according to part A. The error variance of consumption is almost entirely accounted for by the permanent output shock (part C), while investment is explained by a combination of the permanent and transitory shocks. The lack of importance of transitory shocks in explaining consumption is consistent with predictions of the lifecycle permanent-income hypotheses of consumption behavior.

Table $6 \mathrm{~B}$ reports the variance decompositions of the four-variable model. Once again, inflation shocks explain a very small percentage -- less than 10 percent -- of the forecast error variance of either consumption or investment. The contribution of inflation shocks to output variability -- above thirty percent -- is higher than in the five-variable model but with large standard errors. Consumption is once again explained nearly entirely by output shocks, while investment is explained by a combination of the permanent output shocks and the transitory shocks.

The variance decomposition results are instructive for understanding the long-run real effects of inflation. From our cointegration analysis we estimate that permanent changes in inflation have 
fairly large effects on output, investment, and consumption in the long run. However, the variance decompositions reveal that inflation shocks account for very little of the forecast error variances of these same variables. This suggests that, over this long span of data, the exogenous part of the permanent component of inflation has been relatively small.

\section{Analysis of Sub-Periods}

According to the results discussed above, long-term data from the U.S. do not appear to be consistent with models in which either superneutrality holds or in which the only mechanism through which inflation influences real activity in the long run is acting as a tax on consumption and investment. However, it could be argued that these results are driven by special sub-periods of the data such as wars or the Great Depression, which was a period of deflation and low investment. Table 1 and figure 1 give an indication of how different the inflation and other variables' processes have been in the pre-WWI, interwar, and post-1949 periods. To examine the robustness of our results, we estimate the models over two subsamples: the post-war period (1950-1995) and the interwar period $(1918-1941) .^{21}$

The results from the sub-samples are contained in table 7. According to the first row of the table, both sub-periods are characterized by a positive relationship between inflation and the investment-output ratio and a negative relationship between inflation and the consumption-output ratio. The relationship of inflation with the investment ratio is much stronger for the inter-war period than the full sample. The estimate implies that a permanent 1 percentage point drop in inflation is associated with a long-run drop in the share of investment in total GDP of 4 percentage points (e.g., starting from a $14 \%$ share to a $10 \%$ share). This large effect no doubt reflects the dramatic movements in inflation and investment during the Great Depression. Eichengreen (1992) argues persuasively that the direction of causation in this interwar relationship likely goes from monetary

\footnotetext{
${ }^{21}$ The results from the sub-periods must be interpreted with some caution, however, since cointegration and VECM estimation techniques are more appropriate for longer spans of data. 
contraction (and hence a fall in inflation) to investment and output rather than vice versa. This is consistent with the importance attached to inflation shocks in our interwar period variance decomposition results from the estimation of the fully identified structural model (discussed shortly).

In the post-WWII period, the long-run relationship between inflation and investment, although still positive and significant, is considerably smaller than in the full sample: the estimate implies that a permanent 1 percentage point drop in inflation is associated with a drop in the share of investment in total GDP of $2 / 10$ of a percentage point (e.g., starting from a $14 \%$ share to a $13.8 \%$ share).

The variance decomposition results are reported in the final row of the table. In both subperiods, the inflation shock accounts for a large percentage of the forecast error variances of output, consumption, and investment. In the post-WWII period, for example, the inflation shock accounts for over 60 percent of the variance of output (at the two-year horizon), which is approximately 30 to 40 percent more than in the full-sample results of table 6. For investment, the increased importance of inflation shocks during the post-WWII period is of the same order of magnitude. Clearly, the inflation trend became increasingly important relative to the other permanent trends in the latter part of the sample, a result which probably reflects the increased persistence of inflation itself, as noted by Barsky (1987) and others.

The combined analysis of the cointegration vectors and variance decompositions, for the full sample and sub-periods, suggests the following. Over the entire 1889-1995 period, permanent shocks to inflation, when they do occur, have large long-run effects on real variables. However, significant shocks to inflation appear not to occur very frequently during much of the sample. However, the post-WWII period is noticeably different. Although significant "permanent" shocks to inflation are a more regular feature of the data, the long-run effects of a given size shock are much smaller. For instance, the decade average inflation rate fell by about 5 percentage points from the 1970 s to the 1980s. Despite this large permanent drop in the inflation rate, neither investment nor the investment rate fell by as much as would be implied by the full sample estimates. One might conclude from this 
that long-run superneutrality, although a good starting point in explaining real economic fluctuations, is not strictly-speaking a correct description of the data generation process.

Recall that the post-WWII period is characterized by a larger variance of inflation shocks, as well as smaller long-run effects of inflation on real variables for a given size shock. This may well be the consequence of monetary policy having moved increasingly away from "rules" and toward "discretion". Clearly, moving to a more discretionary monetary policy is likely to make monetary policy shocks, and thereby inflation shocks, more volatile. And to the extent that the discretionary stabilization policy is successful, it will also mean that the observed response of real variables to a given size monetary policy shock would be smaller. This latter point has been made by Mankiw (1986), for instance.

\section{Concluding Remarks}

Understanding the long-run real effects of permanent changes in inflation is essential to debates in academic circles concerning the channels of monetary policy transmission, as well as to debates in policymaking circles related to the goal of price stability. Using a new approach, this paper empirically analyzes such effects from a much different analytical perspective than existing studies.

The evidence from long-term U.S. data indicates that the investment rate, and hence implicitly the real rate of interest, is not independent of inflation in the long run. Specifically, a permanent unanticipated rise in inflation is associated with a rise in the investment-output ratio in the long run. This is consistent with the real interest rate falling and a Tobin-type effect. Direct evidence on the Tobin/reverse-Tobin effect confirms this. Our empirical approach does not tell us the exact mechanism that generates a Tobin type effect. We leave as open the question of whether a Tobin type effect holds due to factors such as finite lifetimes, individual heterogeneity, and uncertain lifetimes highlighted in the literature cited in Orphanides and Solow's survey paper, or due to tax distortions of the type highlighted by Feldstein and by Bayoumi and Gagnon, for instance, or possibly due to 
downward rigidty of nominal wages with individual firms experiencing stochastic shocks to the demand for their output, as emphasized recently by Akerlof et al.

Our results, however, do appear to be inconsistent with models that emphasize either superneutrality or only the role of inflation as a tax on consumption or investment, or endogenous growth models with money, which also generate a reverse-Tobin effect. One must bear in mind, though, that our variance decompositions from the full sample, suggest that, while a significant Tobin type effect is found, the role of inflation in explaining the fluctuations in the levels of real variables is very limited, compared to the role played by productivity and fiscal trends. We conclude that realbusiness-cycle models and endogenous growth models appear to be useful approximations in explaining real economic fluctuations. But they are perhaps not the best models, even when extended to incorporate money, for understanding the long-term real effects of inflation, at least in the form in which they are currently popular.

The results from the post-war (1950-1995) and inter-war (1918-1941) subsamples confirm the existence of a Tobin type effect, but differ from the full-sample estimates in two ways. First, the estimated long-run effects on output, investment, and consumption are much larger (smaller) in the inter-war (post-war) period than in the full sample. Second, as measured by the variance decompositions, the inflation trend is quite important in the sub-periods. Comparing the full-sample and post-WWII results suggests that, in those periods when permanent changes in inflation are estimated to have large long-run real effects (pre-WWII), such shocks did not occur often. However, when "permanent" shocks to inflation are a more regular part of the data, as in the post-WWII period, such shocks have smaller long-run effects. A convincing explanation of both of these results could center on the more activist stance of monetary policy in the post-WWII period.

Two further avenues of research are worthy of pursuit. First, it would be a useful extension to incorporate net exports into both the theoretical and empirical analysis and aiso provide evidence on the long-run effects of inflation on this variable. Second, it would be interesting to undertake a crosscountry analysis along similar lines. 


\section{REFERENCES}

Abel, Andrew B. (1985) "Dynamic Behavior of Capital Accumulation in a Cash-In-Advance Model," Journal of Monetary Economics, July, 16, 55-71.

Akerlof, George, William Dickens, and George Perry (1996) "The Macroeconomics of Low Inflation," Brookings Papers on Economic Activity, forthcoming.

Ball, Laurence, N. Gregory Mankiw, and David Romer (1988) "The New Keynesian Economics and the Output Inflation Tradeoff." Brookings Papers on Economic Activity, 1, 1-65.

Barro, Robert J. (1991) "Economic Growth in a Cross-Section of Countries," Quarterly Journal of Economics, May, 106, 407-443.

Barro, Robert J. and Xavier Sala-i-Martin. (1995) Economic Growth (New York: Mc-Graw Hill).

Bayoumi, Tamim and Joseph Gagnon. (1996) "Taxation and Inflation: A New Explanation for International Capital Flows," Journal of Monetary Economics, forthcoming.

Barsky, Robert B. (1987) "The Fisher Hypothesis and the Forecastability and Persistence of Inflation," Journal of Monetary Economics, January, 19, 3-24.

Brock, William A. (1974) "Money and Growth: The Case of Long Run Perfect Foresight," International Economic Review, 15, 750-777.

Cooley, Thomas F. and Gary D. Hansen. (1989) "The Inflation Tax in a Real Business Cycle Model," American Economic Review, September, 79: 4, 733-748.

Dickey, David A. and Wayne A. Fuller. (1979) "Distribution of the Estimators for Autoregressive Time Series With a Unit Root," Journal of the American Statistical Association, June, 74, 427-431.

De Gregorio, Jose. (1993) "Inflation, Taxation, and Long-Run Growth," Journal of Monetary Economics, June, 31, 271-298. 
Eichengreen, Barry. (1992) Golden Fetters: The Gold Standard and the Great Depression, 19191939 (New York: Oxford University Press).

Feldstein, Martin S. (1976) "Inflation, Income Taxes, and the Rate of Interest: A Theoretical Analysis, American Economic Review, 66, 809-820.

Fischer, Stanley. (1983) "Inflation and Growth," NBER working paper, Number 1235.

Fisher, Irving. (1930) The Theory of Interest (New York: Macmillan).

Friedman, Milton, and Anna Schwartz. (1963) A Monetary History of the United States (Princeton: Princeton University Press).

Gomme, Paul. (1993) "Money and Growth Revisited: Measuring the Costs of Inflation in an Endogenous Growth Model," Journal of Monetary Economics, August, 32, 51-77.

Johansen, Soren and Katarina Juselius. (1990) "Maximum Likelihood Estimation and Inference on Cointegration With Application to the Demand for Money," Oxford Bulletin of Economics and Statistics, 52, 169-210.

King, Robert G., Charles I. Plosser, James H. Stock, and Mark W. Watson. (1991) American Economic Review, September, 81, 819-840.

King, Robert G. and Mark W. Watson. (1994) "The Post-War U.S. Phillips Curve: A Revisionist Econometric History," Carnegie-Rochester Conference Series on Public Policy, December, 41, 157-219.

Kwiatowski, Phillips, Schmidt, and Shin. (1992) "Testing the Null Hypothesis of Stationarity Against the Alternative of a Unit Root: How Sure Are We That Economic Time Series Have Unit Roots?" Journal of Economietrics, 54, 159-178.

Mankiw, Gregory N. (1986) "Comment on 'Do Equilibrium Real Business Cycle Theories Explain Postwar U.S. Business Cycles'," NBER Macroeconomics Annual, 1, 139-145.

Mendoza, Enrique G., Maria Milesi-Ferretti, and Patrick Asea. (1995) "Do Taxes Matter For LongRun Growth?: Harberger's Superneutrality Conjecture," International Finance Discussion Paper, Board of Governors of the Federal Reserve System, Number 511, June. 
Mishkin, Frederic S. (1992) "Is the Fisher Effect for Real? A Rexamination of the Relationship Between Inflation and Interest Rates," Journal of Monetary Economics, November, 30:2, 195215.

Orphanides, Athanasios and Robert M. Solow. (1990) "Money, Inflation and Growth," in Handbook of Monetary Economics (edited by B.M. Friedman and F.H. Hahn), (Amsterdam: NorthHolland.

Reimers, H.-E. (1992) "Comparisons of Tests for Multivariate Cointegration," Statistical Papers, 33, 335-359.

Sidrauski, Miguel. (1967) "Inflation and Economic Growth," Journal of Political Economy, 75, 796810.

Stockman, Alan C. (1981) "Anticipated Inflation and the Capital Stock in a Cash-In-Advance Economy," Journal of Monetary Economics, 8, 387-393.

Tobin, James. (1965) "Money and Economic Growth," Econometrica, 33, 671-684.

Wang, Ping and Chong K. Yip. (1992) "Alternative Approaches to Money and Growth," Journal of Money, Credit, and Banking, November, 24:4, 553-562. 


\section{Appendix A: Recursive Representation of the Optimization Problem}

From Bellman, if $V$ is the value function, the maximization problem described in the text has the following recursive representation:

$$
V\left(M_{t}^{d}, K_{t}, P_{t}\right)=\max _{C_{t,} K_{t+1}, M_{t, 1}^{d}}\left\{u\left(C_{t}, 1-N_{t}, \frac{M_{t}^{d}}{P_{t}}\right)+\beta V\left(M_{t+1}^{d}, K_{t+1}, P_{t+1}\right)\right\}
$$

Let the Lagrange multipliers associated with (6) and (7) be $\lambda_{t}$ and $\gamma_{t}$, respectively. Then using

Bellman's equation and imposing $M_{1}^{\prime}=M_{1}$, the first-order necessary conditions of the maximization problem are (6) and the following equations:

$$
\begin{gathered}
u_{c}(.,)=\lambda_{t}+a_{C} \gamma_{t} \\
u_{l}\left(._{,}\right)=\lambda_{t} X_{t}^{\theta} F_{N}(.) \\
\beta V_{1}\left(\cdot_{t+1}\right)=\frac{\lambda_{t}}{P_{t}} \\
\beta V_{2}\left(\cdot_{t+2}\right)=\lambda_{t}+a_{K} \gamma_{t} \\
\gamma_{1}\left\{\frac{\left(M_{t}+Q_{t}\right)}{P_{t}}-a_{c} C_{i}-a_{K}\left[K_{t+1}-(1-\delta) K_{l}\right]\right\}=0
\end{gathered}
$$

\section{Appendix B: Identification and Estimation Strategy}

The structural model in $M A$ form is (29) in the text and reproduced below for convenience:

$$
\Delta X_{t}=\theta(L) \varepsilon_{;} ; \quad \operatorname{var}\left(\varepsilon_{t}\right)=S \equiv\left[\begin{array}{ll}
S_{11} & S_{12} \\
S_{12} & S_{22}
\end{array}\right], \quad \theta(1) \equiv\left[\begin{array}{ll}
\theta & 0
\end{array}\right] \equiv\left[\begin{array}{ll}
\theta_{1} & 0 \\
\theta_{2} & 0
\end{array}\right],
$$

where recall $\varepsilon=\left(\begin{array}{llllll}\varepsilon_{g} & \varepsilon_{\pi} & \varepsilon_{A} & \varepsilon_{l}{ }^{T} & \varepsilon_{2}{ }^{T}\end{array}\right)$ consists of the three permanent and two transitory shocks and $X=(g, \pi, \ln Y, \ln C \cdot \ln I) . S_{i i}(3 \times 3), S_{22}(2 \times 2)$ are the diagnol covariance matrices of the structural 
permanent and transitory disturbances respectively and $S_{k 2}=S_{21}=0$, implying the independence of the permanent and transitory disturbances. The matrix $\theta(5 \times 3)$ is the product of the two matrices given in (31) in the text and for convenience we have partitioned $\theta$ further into $\theta_{1}(3 \times 3)$ and $\theta_{2}(2 \times 3)$, where $\theta_{1}$ is lower triangular.

The reduced-from $V E C M$ can be used to obtain the following reduced-form $M A$ representation:

$$
\Delta X_{r}=C(L) e_{1} ; \quad \operatorname{var}\left(e_{1}\right)=V, \quad C(1)=\left[\begin{array}{l}
C_{1} \\
C_{2}
\end{array}\right]
$$

where for convenience $C(1)$ has been partitioned into its first three rows, $C_{I}(3 \times 5)$, and its last two rows, $C_{2}(2 \times 5)$.

Next we express the structural disturbances as a linear combination of the reduced-form disturbances:

$$
\varepsilon_{t}=P^{-1} e_{i} ; \quad P^{-1}=\left[\begin{array}{l}
P_{1} \\
P_{2}
\end{array}\right]
$$

where $P^{-1}$ has been partitioned for convenience into its first three rows, $P_{l}(3 \times 5)$, and its last two rows, $P_{2}(2 \times 5)$. To show that our model identifies the permanent structural disturbances, we have to demonstrate that under the assumptions given above that $S_{1 l}, S_{22}$ are diagnol matrices, $S_{12}$, $S_{21}$ are null matrices, and $\theta_{I}$ is lower triangular, $P_{I}$ is determined uniquely.

Obtaining the First Three Rows of $P^{-1}\left(P_{\nu}\right)$

From (B1), (B2), and (B3),

$$
\begin{gathered}
\theta(1) \varepsilon_{\iota}=C(1) e_{t} \\
\Rightarrow \theta(1) S \theta(1)^{\prime}=C(1) V C(1)^{\prime} \equiv W \\
\Rightarrow \theta_{1} S_{11} \theta_{1}^{\prime}=W_{11},
\end{gathered}
$$

where $W_{11}$ is the upper left-hand (3x3) submatrix of $W$. It follows directly from the last line of (B4) that the Choleski factor of $W_{I I}$ will give the unique $\theta_{l}$ such that $S_{I I}$ is the identity matrix. Then from the first line of (B4), (B3), and the partitions for $\theta(1)$ and $C(1)$ given in (B1), (B2) respectively, it in turns follows that $P_{1}=\theta_{1}^{-1} C_{1}$. 
Obtaining the Last Two Rows of $P^{-1}\left(P_{2}\right)$

We need to do this to complete our identification. This is to ensure that the transitory disturbances are independent of the permanent disturbances, so that the impulse responses and variance decompositions with respect to the permanent disturbances are really identified and not getting mixed up with the effects of the transitory disturbances.

From (B3), it follows that:

$$
\begin{gathered}
S=P^{-1} V P^{-1} \\
\Rightarrow S_{12}=P_{1} V P_{2}^{\prime} \\
S_{22}=P_{2} V P_{2}^{\prime}
\end{gathered}
$$

We must choose $P_{2}$ such that $S_{12}=0$ and $S_{22}$ is invertible. This can be done by picking any two linearly independent solutions to $P_{1} V x=0$, where $x$ is a $(5 \times 1)$ vector of unknowns being solved for. One way to do this is to pick the two independent eigenvectors associated with the non-zero eigenvalues of the matrix $M$, where $M=I-A^{\prime}\left(A A^{\prime}\right)^{-1} A$, with $A \equiv P_{I} V$. Since $M x=\lambda_{i} x$, where the $\lambda_{i} \mathrm{~s}$ are the eigenvalues of $M, \mathrm{AM}=0$ (which is true by construction) implies $A x=0$. Note that this is just one way to obtain $P_{2}$ and that is why the transitory disturbances are not individually identified.

Right now, $S_{1 /}$ is the identity matrix and $\theta$ is not in the exact form given by (30), in the sense of having 1's on the leading diagnol. To put $\theta$ in the required form, we can renormalize the size of the shocks such that the long-run response of a variable to its own shock is normalized to be unity. This will put $\theta$ in the form of (30) and make $S_{l l}$ diagnol only, rather than the identity matrix.

\section{DATA APPENDIX}

(1) $\mathrm{Y}=$ real gross domestic product in billions of 1987 dollars. The sources are Kendrick (1961) table A-IIa from 1889-1928, and the National Income and Product Accounts (NIPA) from 1929-1995 (U.S. Department of Commerce (1993) and various issues of the Survey of Current Business).

(2) $\mathrm{C}=$ real consumption expenditures in billions of 1987 dollars. Sources are the same as for $\mathrm{Y}$. 
(3) $\mathrm{I}=$ real gross private domestic investment in billions of 1987 dollars. Sources are the same as for $\mathrm{Y}$.

(4) $\mathrm{G}=$ real federal government expenditures on goods and services in billions of 1987 dollars. Sources are the same as for $Y$.

(5) $\mathrm{P}=$ GDP deflator, taken as the ratio of nominal GDP to real GDP $(1987=1.00)$. Nominal GDP data are taken from Kendrick (1961) table A-Ilb from 1889-1928, and NIPA from 1929-1995.

(6) POP = total resident population of the United States, taken from U.S. Bureau of the Census (1976 and 1992) and updates.

\section{REFERENCES}

Kendrick, John W. (1961) Productivity Trends in the United States. General Series, no.71. Princeton. NJ: Princeton University Press (for NBER).

United States Department of Commerce, Bureau of Economic Analysis (1993) National Income and Product Accounts, Volume I, 1929-58 and Volume II, 1959-88 (Washington, DC).

Survey of Current Business (Washington, DC).

United States Bureau of the Census (1976) Statistical History of the United States (Washington, DC). (1992) Statistical Abstract of the United States (Washington, DC). 
Table 1: Summary Statistics - Means, and Standard Deviations

\begin{tabular}{c|c|c|c|c|c}
\hline \hline & $\begin{array}{c}\text { Full Sample } \\
(1889-1995)\end{array}$ & $\begin{array}{c}\text { Pre-WWI } \\
(1889-1914)\end{array}$ & $\begin{array}{c}\text { Inter-War } \\
(1918-41)\end{array}$ & $\begin{array}{c}\text { Post-War } \\
(1950-95)\end{array}$ & $\begin{array}{c}\text { Post-OPEC } \\
(1973-95)\end{array}$ \\
\hline $\mathrm{G} / \mathrm{Y}$ & 19.4 & 11.6 & 18.3 & 21.7 & 19.0 \\
& $(8.56)$ & $(0.92)$ & $(5.66)$ & $(3.19)$ & $(0.69)$ \\
$\pi$ & 3.05 & 0.81 & 0.36 & 4.30 & 5.56 \\
& $(5.54)$ & $(2.72)$ & $(7.03)$ & $(2.42)$ & $(2.48)$ \\
$\mathrm{C} / \mathrm{Y}$ & 63.8 & 64.1 & 67.8 & 63.3 & 66.1 \\
& $(5.40)$ & $(2.10)$ & $(4.52)$ & $(3.27)$ & $(1.52)$ \\
$\mathrm{I} / \mathrm{Y}$ & 16.6 & 22.9 & 13.7 & 15.8 & 16.1 \\
& $(5.41)$ & $(3.13)$ & $(4.98)$ & $(1.25)$ & $(1.32)$ \\
$\Delta \mathrm{y}$ & 3.13 & 3.49 & 2.92 & 3.08 & 2.39 \\
& $(5.92)$ & $(5.82)$ & $(7.29)$ & $(2.40)$ & $(2.15)$ \\
& & & & \\
\hline \hline
\end{tabular}

Notes: $\mathrm{G} / \mathrm{Y}, \mathrm{C} / \mathrm{Y}$, and $\mathrm{I} / \mathrm{Y}$ denote, respectively, the ratios of real government purchases, real consumption, and real investment to real GDP; $\pi$ denotes the annual percentage change in the GDP deflator, and $\Delta y$ denotes real GDP growth. Reported above is the mean and standard deviation (in parenthesis) of each series, in percent.

Table 2: Unit Roots Tests

\begin{tabular}{|c|c|c|c|c|c||}
\hline Variable & $\begin{array}{c}\text { ADF } \\
\text { (level) }\end{array}$ & $\begin{array}{c}\text { ADF } \\
\text { (1st diff. })\end{array}$ & $\begin{array}{c}\text { KPSS } \\
\text { (level) }\end{array}$ & $\begin{array}{c}\text { KPSS } \\
(1901-92)\end{array}$ & $\begin{array}{c}\text { ADF- level } \\
\text { [war dynam] }\end{array}$ \\
\hline \hline $\mathrm{c}$ & -2.14 & $-4.24^{*}$ & $0.24^{* *}$ & $2.12^{* *}$ & -2.05 \\
\hline $\mathrm{i}$ & -2.24 & $-4.80^{* *}$ & $0.28^{* *}$ & $0.47^{* *}$ & -2.24 \\
\hline $\mathrm{y}$ & -2.95 & $-4.57^{* *}$ & 0.08 & $2.02^{* *}$ & -2.82 \\
\hline$\pi$ & $-3.51^{*}$ & $-6.00^{* *}$ & 0.05 & $0.25^{* *}$ & -2.62 \\
\hline $\mathrm{G} / \mathrm{Y}$ & -2.28 & $-5.98^{* *}$ & $0.65^{*}$ & $0.65^{* *}$ & -0.49 \\
\hline
\end{tabular}

Notes: c, i, and y denote, respectively, the logs of real per capita consumption, investment, and GDP; $\pi$ denotes the annual percentage change in the CPI, and G/Y is the ratio of government purchases to GDP. ADF denotes the Augmented Dickey-Fuller test statistic for the unit root null hypothesis. KPSS denotes the Kwiatkowski, Phillips, Schmidt, and Shin test of the null of stationarity. ADF [war dynam] refers to the ADF tests that allow the short-run dynamics for the world war years to be different. The sample period is 1889-1995 except in the final column, which displays results for the 1901-95 sample period. A \#, *, and ** indicates rejection of the null at $10 \%, 5 \%$, and $1 \%$, respectively. A time trend is included in all tests for all variables except $(G / Y)$. A lag length of 5 is used in all tests. 
Table 3: Tests of Cointegrating rank

\section{Results for 5 Variable Model}

\begin{tabular}{|c|c|c|c|c|c|c|}
\hline $\begin{array}{l}\mathrm{H}_{0}: \mathrm{CI} \\
\text { rank=p }\end{array}$ & $\begin{array}{l}\text { Max } \\
\text { eigenvalue } \\
\text { statistic }\end{array}$ & $\begin{array}{c}\text { Max } \\
\text { eigenvalue } \\
\text { statistic } \\
\text { (df) }\end{array}$ & $\begin{array}{c}95 \% \\
\text { critical } \\
\text { value }\end{array}$ & $\begin{array}{c}\text { Trace } \\
\text { statistic }\end{array}$ & $\begin{array}{c}\text { Trace } \\
\text { statistic } \\
\text { (df) }\end{array}$ & $\begin{array}{c}95 \% \\
\text { critical } \\
\text { value }\end{array}$ \\
\hline $\mathrm{p}=0$ & $44.84^{* *}$ & $38.31^{*}$ & 33.5 & $106.1 * *$ & $90.69 * *$ & 68.5 \\
\hline $\mathrm{p} \leq 1$ & $28.08 * *$ & $24.0^{*}$ & 27.1 & $61.3^{* *}$ & $52.38^{*}$ & 47.2 \\
\hline $\mathrm{p} \leq 2$ & 19.85 & 16.96 & 21.0 & $33.23 *$ & 28.39 & 29.7 \\
\hline $\mathrm{p} \leq 3$ & 13.26 & 11.33 & 14.1 & 13.38 & 11.43 & 15.4 \\
\hline $\mathrm{p} \leq 4$ & 0.12 & 0.10 & 3.8 & 0.12 & 0.11 & 3.8 \\
\hline & System: & $\begin{array}{l}\pi, y, c, i \\
\text { ant includ }\end{array}$ & $\begin{array}{l}\text { mple } \\
\text { the de }\end{array}$ & $\begin{array}{l}1995 \\
\text { tic com }\end{array}$ & $\mathrm{gth}=3$ & \\
\hline
\end{tabular}

\section{Results for 4 Variable Model}

\begin{tabular}{|c|c|c|c|c|c|c|}
\hline $\begin{array}{l}\mathrm{H}_{0}: \mathrm{CI} \\
\text { rank=p }\end{array}$ & $\begin{array}{c}\text { Max } \\
\text { eigenvalue } \\
\text { statistic }\end{array}$ & $\begin{array}{c}\text { Max } \\
\text { eigenvalue } \\
\text { statistic } \\
\text { (df) }\end{array}$ & $\begin{array}{c}95 \% \\
\text { critical } \\
\text { value }\end{array}$ & $\begin{array}{c}\text { Trace } \\
\text { statistic }\end{array}$ & $\begin{array}{c}\text { Trace } \\
\text { statistic } \\
\text { (df) }\end{array}$ & $\begin{array}{c}95 \% \\
\text { critical } \\
\text { value }\end{array}$ \\
\hline $\mathrm{p}=0$ & $42.3 * *$ & $37.4^{* *}$ & 27.1 & $82.6^{* *}$ & $73.0 * *$ & 47.2 \\
\hline $\mathrm{p} \leq 1$ & $27.4^{* *}$ & $24.2 * *$ & 21.0 & $40.3^{* *}$ & $35.6^{* *}$ & 29.7 \\
\hline$p \leq 2$ & 12.7 & 11.2 & 14.1 & 12.8 & 11.4 & 15.4 \\
\hline $\mathrm{p} \leq 3$ & 0.22 & 0.20 & 3.8 & 0.22 & 0.20 & 3.8 \\
\hline
\end{tabular}

NOTES: $(1) *(* *)$ indicates significance at the $5 \%(1 \%)$. (2) The maximum eigenvalue static (df) and trace statistic $(\mathrm{df})$ apply a simple small-sample correction to Johansen's statistics (replacing $\mathrm{T}$ by $\mathrm{T}-\mathrm{nm}$, where $\mathrm{T}=$ number observations, $n=$ number of variables, $\mathrm{m}=$ number of lags) as recommended by Reimers (1992). 
Table 4: Estimates of Structural Cointegrating Vectors

\begin{tabular}{|c|c|c|c|c|}
\hline \multirow{3}{*}{ Variable } & \multicolumn{4}{|c|}{ Coefficient } \\
\hline & \multicolumn{2}{|c|}{ Five-Variable System } & \multicolumn{2}{|c|}{ Four-Variable System ${ }^{1}$} \\
\hline & Vector 1 & Vector 2 & Vector 1 & Vector 2 \\
\hline c & $1.00^{r}$ & $0.00^{r}$ & $1.00^{r}$ & $0.00^{r}$ \\
\hline $\mathrm{i}$ & $0.00^{r}$ & $1.00^{r}$ & $0.00^{r}$ & $1.00^{r}$ \\
\hline$y$ & $-1.00^{r}$ & $-1.00^{r}$ & $-1.00^{r}$ & $-1.00^{x}$ \\
\hline$\pi$ & $\begin{array}{c}4.02 \\
(0.72)\end{array}$ & $\begin{array}{l}-5.58 \\
(1.17)\end{array}$ & $\begin{array}{l}11.0 \\
(1.95)\end{array}$ & $\begin{array}{l}-6.52 \\
(1.26)\end{array}$ \\
\hline $\mathrm{G} / \mathrm{Y}$ & $\begin{array}{l}-0.63 \\
(0.39)\end{array}$ & $\begin{array}{c}3.84 \\
(0.63)\end{array}$ & --- & --- \\
\hline Lag length & \multicolumn{2}{|c|}{3} & \multicolumn{2}{|c|}{3} \\
\hline$\chi^{2}(2)[p \text {-value }]^{2}$ & \multicolumn{2}{|c|}{$16.5[.00]$} & \multicolumn{2}{|c|}{$17.7[.00]$} \\
\hline $\begin{array}{l}\text { Coefficient on y } \\
\text { (unrestricted) }\end{array}$ & $\begin{array}{l}-1.075 \\
(0.024)\end{array}$ & $\begin{array}{l}-0.99 \\
(0.09)\end{array}$ & $\begin{array}{l}-1.08 \\
(0.03)\end{array}$ & $\begin{array}{l}-0.97 \\
(0.10)\end{array}$ \\
\hline
\end{tabular}

Notes: Standard errors are in parentheses. A $\mathrm{r} "$ indicates that the coefficient was constrained to the value shown. (1) In the four-variable system, GY is treated as stationary and exogenous; its contemporaneous value and three lagged values are included as deterministic components of the VAR equations. (2) This is the Chi-squared statistic associated with the likelihood ratio test of the null hypothesis that the restrictions imposed on the output variable in the two vectors are jointly satisfied. "P-value" refers to the marginal significance level of the $\chi^{2}$ statistic. (3) The coefficient on y from a separate estimate in which the unit coefficient restriction is relaxed.

Table 5: Estimates of Structural Parameters

\begin{tabular}{l|cccc}
\hline \multicolumn{1}{c|}{ Model } & \multicolumn{4}{c}{ Coefficient } \\
\cline { 2 - 5 } & $\beta_{N}+\beta_{Y}$ & $\beta_{N}+\beta_{C}$ & $\beta_{N}+\beta_{I}$ & $\beta_{G}$ \\
\hline \hline \multirow{2}{*}{ 5-Variable System } & 7.47 & 3.45 & 13.1 & 0.48 \\
& $(2.14)$ & $(1.77)$ & $(2.44)$ & $(0.18)$ \\
4-Variable System & 20.7 & 9.74 & 27.3 & $\ldots$ \\
& $(5.84)$ & $(5.09)$ & $(5.98)$ & \\
\hline \hline
\end{tabular}

Notes: Standard errors, shown in parenthesis, were computed by Monte Carlo simulation using 1,000 replications. 
Table 6A: Variance Decompositions: Five-Variable Model

A. Fraction of the forecast error variance attributed to the fiscal shock

\begin{tabular}{cccccc} 
Horizon: & $\mathrm{G} / \mathrm{Y}$ & $\pi$ & $\mathrm{y}$ & $\mathrm{c}$ & $\mathrm{i}$ \\
\hline 1 & 77.8 & 42.9 & 49.7 & 0.17 & 0.18 \\
& $(17.6)$ & $(14.9)$ & $(16.3)$ & $(7.35)$ & $(8.43)$ \\
2 & 71.1 & 37.9 & 53.2 & 1.86 & 1.45 \\
& $(17.4)$ & $(13.5)$ & $(14.6)$ & $(6.96)$ & $(8.05)$ \\
5 & 62.3 & 32.8 & 51.1 & 1.82 & 1.94 \\
& $(15.4)$ & $(11.4)$ & $(13.3)$ & $(6.52)$ & $(7.23)$ \\
20 & 60.8 & 32.4 & 51.0 & 1.92 & 2.87 \\
& $(14.9)$ & $(11.1)$ & $(13.2)$ & $(6.47)$ & $(6.97)$
\end{tabular}

B. Fraction of the forecast error variance attributed to the inflation shock

\begin{tabular}{|c|c|c|c|c|c|}
\hline Horizon: & $\mathrm{G} / \mathrm{Y}$ & $\pi$ & $y$ & c & $\mathrm{i}$ \\
\hline 1 & $\begin{array}{c}1.57 \\
(4.33)\end{array}$ & $\begin{array}{c}2.68 \\
(6.64)\end{array}$ & $\begin{array}{c}17.5 \\
(12.0)\end{array}$ & $\begin{array}{c}5.13 \\
(8.31)\end{array}$ & $\begin{array}{c}1.94 \\
(7.01)\end{array}$ \\
\hline 2 & $\begin{array}{c}9.37 \\
(6.30)\end{array}$ & $\begin{array}{c}8.89 \\
(6.56)\end{array}$ & $\begin{array}{c}18.5 \\
(10.6)\end{array}$ & $\begin{array}{c}5.35 \\
(7.58)\end{array}$ & $\begin{array}{c}3.31 \\
(6.48)\end{array}$ \\
\hline 5 & $\begin{array}{c}18.3 \\
(6.95)\end{array}$ & $\begin{array}{c}14.8 \\
(7.01)\end{array}$ & $\begin{array}{c}17.8 \\
(9.54)\end{array}$ & $\begin{array}{c}5.63 \\
(6.64)\end{array}$ & $\begin{array}{c}14.1 \\
(6.27)\end{array}$ \\
\hline 20 & $\begin{array}{c}19.0 \\
(7.03)\end{array}$ & $\begin{array}{c}15.3 \\
(7.04)\end{array}$ & $\begin{array}{c}17.9 \\
(9.43)\end{array}$ & $\begin{array}{c}5.77 \\
(6.66)\end{array}$ & $\begin{array}{c}15.7 \\
(6.68)\end{array}$ \\
\hline
\end{tabular}

C. Fraction of the forecast error variance attributed to the output shock

\begin{tabular}{cccccc} 
Horizon: & $\mathrm{G} / \mathrm{Y}$ & $\pi$ & $\mathrm{y}$ & $\mathrm{c}$ & $\mathrm{i}$ \\
\hline 1 & 1.93 & 4.06 & 28.8 & 90.9 & 25.1 \\
& $(6.54)$ & $(6.83)$ & $(15.8)$ & $(14.1)$ & $(13.0)$ \\
2 & 3.71 & 7.27 & 24.2 & 83.9 & 28.6 \\
& $(7.08)$ & $(7.79)$ & $(12.4)$ & $(12.7)$ & $(11.8)$ \\
5 & 3.61 & 6.81 & 23.9 & 81.4 & 24.7 \\
& $(6.26)$ & $(6.87)$ & $(11.2)$ & $(11.7)$ & $(9.95)$ \\
20 & 3.90 & 6.74 & 23.9 & 81.0 & 24.3 \\
& $(6.16)$ & $(6.75)$ & $(11.1)$ & $(11.6)$ & $(9.46)$ \\
& & & & & \\
\hline
\end{tabular}

Notes: Standard errors, shown in parenthesis, were computed by Monte Carlo simulation using 1,000 replications. 
Table 6B: Variance Decompositions: Four-Variable Model

A. Fraction of the forecast error variance attributed to the inflation shock

\begin{tabular}{ccccc} 
Horizon: & $\pi$ & $\mathrm{y}$ & $\mathrm{c}$ & $\mathrm{i}$ \\
\hline \multirow{2}{*}{1} & 2.80 & 34.1 & 5.23 & 1.89 \\
& $(7.70)$ & $(18.6)$ & $(8.98)$ & $(7.63)$ \\
2 & 8.04 & 34.7 & 7.80 & 1.86 \\
& $(7.22)$ & $(18.1)$ & $(8.44)$ & $(7.12)$ \\
5 & 10.8 & 38.8 & 7.92 & 4.78 \\
& $(7.91)$ & $(14.5)$ & $(7.44)$ & $(6.74)$ \\
20 & 11.0 & 39.6 & 8.16 & 6.31 \\
& $(8.01)$ & $(14.2)$ & $(7.44)$ & $(6.65)$
\end{tabular}

B. Fraction of the forecast error variance attributed to the output shock

\begin{tabular}{ccccc} 
Horizon: & $\pi$ & $\mathrm{y}$ & $\mathrm{c}$ & $\mathrm{i}$ \\
\hline 1 & 0.11 & 56.6 & 94.4 & 37.1 \\
& $(3.89)$ & $(19.1)$ & $(12.0)$ & $(15.8)$ \\
2 & 2.89 & 55.5 & 86.2 & 39.0 \\
& $(5.24)$ & $(18.0)$ & $(11.0)$ & $(14.7)$ \\
5 & 3.24 & 50.0 & 83.5 & 36.6 \\
& $(5.13)$ & $(14.6)$ & $(10.2)$ & $(13.3)$ \\
20 & 3.21 & 49.0 & 83.2 & 36.5 \\
& $(5.13)$ & $(14.4)$ & $(10.3)$ & $(13.0)$ \\
\hline
\end{tabular}

Notes: Standard errors, shown in parenthesis, were computed by Monte Carlo simulation using 1,000 replications. 
Table 7: Analysis of Sub-periods

\begin{tabular}{|c|c|c|c|c|}
\hline \multirow[b]{2}{*}{ Estimates } & \multicolumn{4}{|c|}{ Model } \\
\hline & $\begin{array}{l}\text { 5-Var., Post-war } \\
\quad(1950-95)\end{array}$ & $\begin{array}{l}\text { 5-Var., Inter-war } \\
\quad(1918-41)\end{array}$ & $\begin{array}{l}\text { 4-Var., Post-war } \\
(1950-95)\end{array}$ & $\begin{array}{l}\text { 4-Var., Inter-war } \\
(1918-41)\end{array}$ \\
\hline Cointegrating vectors: & $\underline{\pi} \quad \underline{G} / \mathrm{Y}$ & $\underline{\pi} \quad \underline{G / Y}$ & $\underline{\pi}$ & $\underline{\pi}$ \\
\hline (1) $\left[1.0^{\mathrm{r}}(\mathrm{c}-\mathrm{y}), \pi, \mathrm{G} / \mathrm{Y}\right]$ & $0.71,1.87$ & $6.38,-3.27$ & $1.01,-\cdots$ & $2.24, \ldots$ \\
\hline (2) $\left[1.0^{r}(i-y), \pi, G / Y\right]$ & $-1.00,0.67$ & $-29.2,22.6$ & $-0.95,---$ & $-11.3, \cdots$ \\
\hline $\begin{array}{c}\text { Structural parameters: } \\
\left(\beta_{N}+\beta_{Y}, \beta_{N}+\beta_{C}, \beta_{N}+\beta_{l}, \beta_{G}\right)\end{array}$ & $\begin{array}{l}2.69,1.98 \\
3.69,-1.49\end{array}$ & $\begin{array}{l}11.7,5.35 \\
40.9,0.78\end{array}$ & $\begin{array}{l}1.51,0.50 \\
2.46,---\end{array}$ & $\begin{array}{c}4.90,2.66 \\
16.2,---\end{array}$ \\
\hline Forecast Error VDCs ${ }^{1}$ : & & & & \\
\hline $\begin{array}{l}\text { (1) Pct. due to fiscal shock } \\
{[G / Y, \pi, y, c, i ; 2 \text {-year }]}\end{array}$ & $\begin{array}{c}65.6,20.6,6.55 \\
22.8,16.7\end{array}$ & $\begin{array}{c}64.4,38.1,17.5 \\
5.94,35.3\end{array}$ & $-\cdots$ & $\ldots$ \\
\hline $\begin{array}{l}\text { (2) Pct. due to inflation shock } \\
{[G / Y, \pi, y, c, i ; 2 \text {-year }]}\end{array}$ & $\begin{array}{c}15.6,3.62,62.4 \\
43.8,31.2\end{array}$ & $\begin{array}{c}15.9,6.49,50.2 \\
50.7,51.8\end{array}$ & $\begin{array}{c}-10.7,64.1 \\
24.8,48.4\end{array}$ & $\begin{array}{c}--, 45.9,89.9 \\
58.0,84.9\end{array}$ \\
\hline $\begin{array}{l}\text { (3) Pct. due to output shock } \\
{[G / Y, \pi, y, c, i ; 2 \text {-year] }}\end{array}$ & $\begin{array}{c}13.6,70.9,28.6 \\
32.2,35.8\end{array}$ & $\begin{array}{c}7.80,9.12,27.9 \\
41.7,7.76\end{array}$ & $\begin{array}{c}--, 24.4,25.0 \\
\quad 65.2,23.7\end{array}$ & $\begin{array}{c}--, 22.9,6.28 \\
39.0,6.18\end{array}$ \\
\hline
\end{tabular}

Notes: A " $\mathrm{r}$ " indicates that the coefficient was constrained to the value shown. (1) The fraction of the forecast error variance of each variable attributed to the fiscal, inflation, and output shocks, at the 2-year horizon. 
Figure 1. Data in Levels
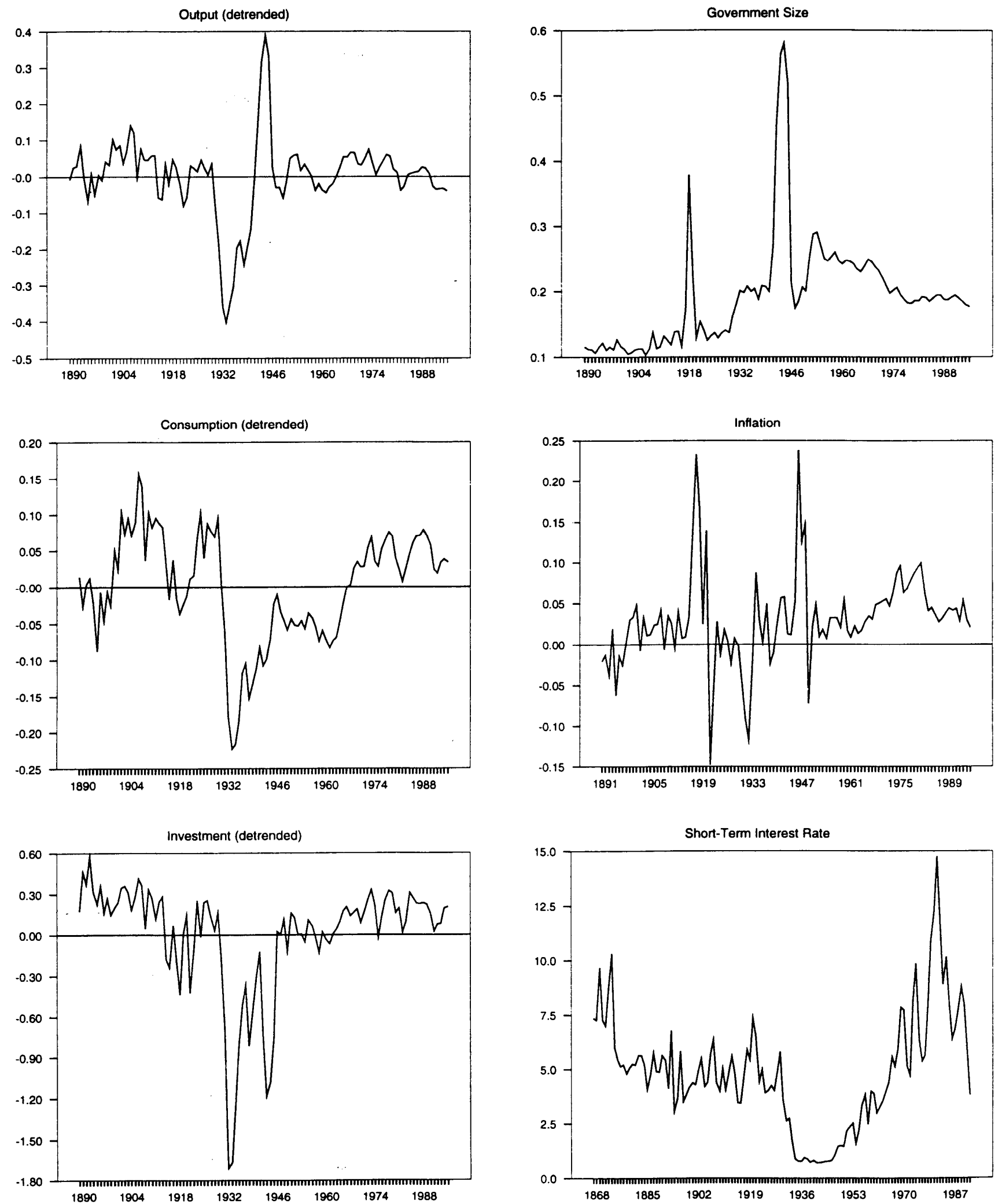
Figure 2. Autocorrelations - Levels
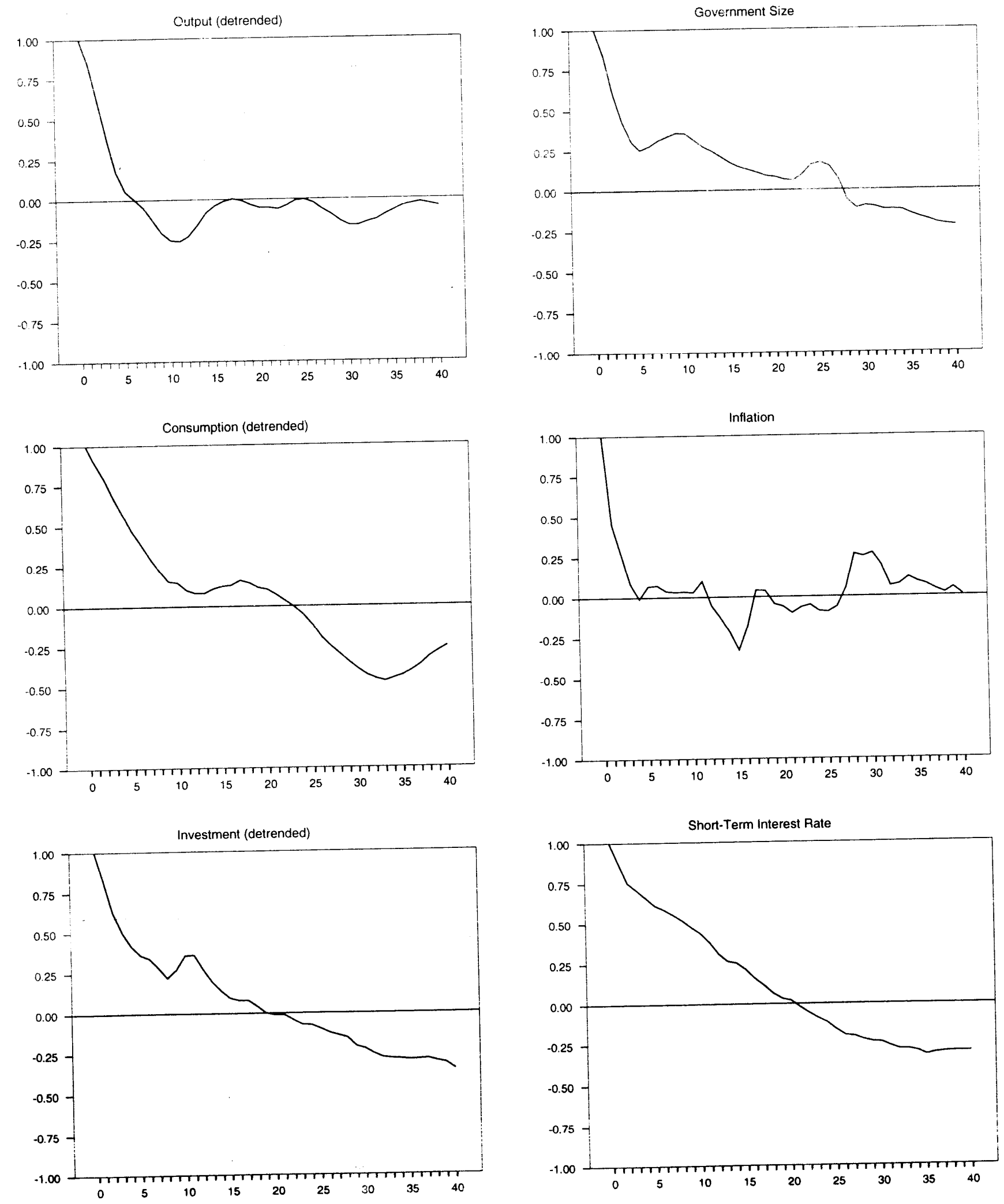


\section{International Finance Discussion Papers}

IFDP

Number

566

565

564

563

562

561 Inflation-Adjusted Potential Output

560 The Management of Financial Risks at German

Nonfinancial Firms: The Case of Metallgesellschaft

559 Broad Money Demand and Financial Liberalization in Greece

$558 \quad$ Stockholding Behavior of U.S. Households: Evidence from the 1983-89 Survey of Consumer Finances

557 Firm Size and the Impact of Profit-Margin Uncertainty on Investment: Do Financing Constraints Play a Role?

556 Regulation and the Cost of Capital in Japan: A Case Study

555 The Sovereignty Option: The Quebec Referendum and Market Views on the Canadian Dollar

554 Real Exchange Rates and Inflation in Exchange-Rate Based Stabilizations: An Empirical Examination $\underline{\text { Author(s) }}$

Shaghil Ahmed

John H. Rogers

Chan Huh

Nita Ghei

Steven B. Kamin

Jeffrey A. Frankel

Sergio L. Schmukler

Nathan Sheets

Simona Boata

Jane T. Haltmaier

Allen B. Frankel

David E. Palmer

Neil R. Ericsson

Sunil Sharma

Carol C. Bertaut

Vivek Ghosal

Prakash Loungani

John Ammer

Michael S. Gibson

Michael P. Leahy

Charles P. Thomas

Steven B. Kamin .

Please address requests for copies to International Finance Discussion Papers, Division of International Finance, Stop 24, Board of Governors of the Federal Reserve System, Washington, DC 20551. 


\section{International Finance Discussion Papers}

IFDP

Number

553

552

551

550

549 $\underline{\text { Titles }}$

Author(s)

$\underline{1996}$

Macroeconomic State Variables as Determinants

of Asset Price Covariances

The Tequila Effect: Theory and Evidence from

Argentina

The Accumulation of Human Capital: Alternative Methods and Why They Matter

Alternatives in Human Capital Accumulation: Implications for Economic Growth

More Evidence on the Link between Bank

Health and Investment in Japan

The Syndrome of Exchange-Rate-Based

Stabilization and the Uncertain Duration of

Currency Pegs

German Unification: What Have We Learned from Multi-Country Models?

Returns to Scale in U.S. Production: Estimates and Implications

Mexico's Balance-of-Payments Crisis: A Chronicle of Death Foretold

The Twin Crises: The Causes of Banking and Balance-of-Payments Problems

High Real Interest Rates in the Aftermath of Disinflation: Is it a Lack of Credibility?

Precautionary Portfolio Behavior from a Life-Cycle Perspective

Using Options Prices to Infer PDF's for Asset Prices: An Application to Oil Prices During the Gulf Crisis

Monetary Policy in the End-Game to Exchange-Rate Based Stabilizations: The Case of Mexico
John Ammer

Martín Uribe

Murat F. Iyigun

Ann L. Owen

Murat F. Iyigun

Ann L. Owen

Michael S. Gibson

Enrique G. Mendoza

Martin Uribe

Joseph E. Gagnon

Paul R. Masson

Warwick J. McKibbin

Susanto Basu

John G. Fernald

Guillermo A. Calvo

Enrique G. Mendoza

Graciela L. Kaminsky

Carmen M. Reinhart

Graciela L. Kaminsky

Leonardo Leiderman

Carol C. Bertaut

Michael Haliassos

William R. Melick

Charles P. Thomas

Steven B. Kamin

John H. Rogers 


\section{International Finance Discussion Papers}

IFDP

Number
Titles

1996

539 Comparing the Welfare Costs and the Initial Dynamics of Alternative Temporary Stabilization Policies

538 Long Memory in Inflation Expectations: Evidence from International Financial Markets

537 Using Measures of Expectations to Identify the Effects of a Monetary Policy Shock

$536 \quad$ Regime Switching in the Dynamic Relationship between the Federal Funds Rate and Innovations in Nonborrowed Reserves

535 The Risks and Implications of External Financial Shocks: Lessons from Mexico

534 Currency Crashes in Emerging Markets: An Empirical Treatment

533 Regional Patterns in the Law of One Price: The Roles of Geography Vs. Currencies
Author(s)

Martin Uribe

Joseph E. Gagnon

Allan D. Brunner

Chan Huh

Edwin M. Truman

Jeffrey A. Frankel Andrew K. Rose

Charles Engel John H. Rogers 